\title{
Reinforcement or compensation? Parental responses to children's revealed human capital levels
}

\section{Wei Fan ${ }^{1} \cdot$ Catherine Porter ${ }^{2}$ (iD}

Received: 31 July 2018 / Accepted: 21 August 2019 / Published online: 6 September 2019

(C) The Author(s) 2019

\begin{abstract}
A small but increasing body of literature finds that parents invest in their children unequally. However, the evidence is contradictory, and providing convincing causal evidence of the effect of child ability on parental investment in a low-income context is challenging. This paper examines how parents respond to the differing abilities of primary school-aged Ethiopian siblings, using rainfall shocks during the critical developmental period between pregnancy and the first 3 years of a child's life to isolate exogenous variations in child ability within the household, observed at a later stage than birth. The results show that on average parents attempt to compensate disadvantaged children through increased cognitive investment. The effect is significant, but small in magnitude: parents provide about $3.9 \%$ of a standard deviation more in educational fees to the lower-ability child in the observed pair. We provide suggestive evidence that families with educated mothers, smaller household size and higher wealth compensate with greater cognitive resources for a lower-ability child.
\end{abstract}

Keywords Children · Human capital formation · Parental investment · Intrahousehold resource allocation

JEL Classification D13 · J1

Responsible editor: Junsen Zhang

The data are from Young Lives, a 15-year study of the changing nature of childhood poverty in Ethiopia, India, Peru and Vietnam (www.younglives.org.uk). Young Lives was core funded by UK aid from the Department for International Development (DFID) from 2001-2018.

Catherine Porter

catherine.porter@lancaster.ac.uk

Wei Fan

wf6@hw.ac.uk

1 Heriot-Watt University, Edinburgh, EH14 4AS, UK

2 Lancaster University Management School, Lancaster, LA1 4YX, UK 


\section{Introduction}

A large body of evidence has developed during the past three decades showing that in utero and early life conditions have a significant impact on children's early life ability, subsequent development and therefore on outcomes in adulthood (surveyed by Currie and Almond (2011) and Almond et al. (2018)). Most of these studies are reduced-form estimates of the total effect of an early life shock or adverse event on final adult health. However, ability in early life impacts later human capital not only through the biological channel (Heckman 2007) but also through the channel of parental involvement-in theory, parents can either reinforce or compensate for revealed early ability. It is then an empirical question whether parental actions amplify or mute the ultimate effect of early life shocks and circumstances on adult human capital outcomes.

Our paper contributes to this latter research question, which is of direct policy relevance. The current literature comprises a body of empirical evidence that appears somewhat contradictory, containing studies that document both compensatory and reinforcing parental behaviour. Attempting to clearly identify such effects given the econometric concerns is extremely difficult, and could be one reason for the apparently conflicting results. Alternatively, there may be important differences across country contexts (either cultural or economic) that lead to such different conclusions.

Our contribution extends the existing literature in three specific ways. First, we examine the response of parents to differences in child cognitive ability in early childhood in a low-income country, using a measure of ability rather than a proxy like birth weight or height. We are aware of only two previous studies that have analysed parental responses to observed cognitive ability beyond birth. Frijters et al. (2013) find that parents reinforce cognitive resources in response to differences in cognitive ability in the USA. Ayalew (2005) also finds reinforcing effects, but these results are based on estimates from only one village in Ethiopia. ${ }^{1}$

Second, we use both sibling fixed-effects and a plausibly exogenous source instrument (rainfall in early life) for variation in cognitive ability to more convincingly identify parental responses, rather than relying on within-twin estimation, since twins are not the ideal group on which to study such effects (Bhalotra and Clarke 2018). Other instruments have been utilised in the literature. Frijters et al. (2013) use handedness as an instrument of a child's ability, the validity of which has been contested (Grätz and Torche 2016). Leight (2017) uses grain yields as a plausible instrument for differences in ability proxied by height-for-age. There is an extremely careful literature that has analysed whether parents compensate or reinforce specific (plausibly exogenous) policies and events experienced in childhood (Halla et al. 2014; Adhvaryu and Nyshadham 2016), which is highly informative, but may only be generalisable to larger policy shocks, whereas our use of variation in rainfall could be seen as 'normal' shocks to childhood experienced by children in low-income countries (Maccini and Yang 2009).

\footnotetext{
${ }^{1}$ Other results on health in the study are based on a much larger sample.
} 
Third, we descriptively examine heterogeneity in parental responses across socioeconomic status, in a low-income setting. Such heterogeneity has been examined, but only in country contexts that are more developed than Ethiopia (Cabrera-Hernandez 2016; Hsin 2012; Grätz and Torche 2016; Restrepo 2016). To preview our results, we find that on average, parents provide more cognitive investment to the lower-ability child to reduce intrahousehold inequality. The compensatory parental responses appear to be concentrated in relatively higher-SES families. Specifically, we find suggestive evidence that families with educated mothers, smaller household size and higher wealth compensate through a higher level of cognitive investment when there are differences in ability, while families with non-educated mothers, larger size and lower wealth exhibit only small and modest compensatory behaviours.

The paper proceeds as follows. In the next section, we briefly review the relevant literature, and in subsequent sections then present our data, including the cognitive ability measures, followed by our econometric approach, our results and robustness checks and a concluding discussion.

\section{Literature review}

There are two competing theories on the direction of parental responses to observed ability in their children, both originating from theoretical models which are by now more than 40 years old. Becker and Tomes (1976) predict that parents reinforce differences in child ability by investing more in the high-ability child, under the assumption that marginal return to investment is higher when the ability of the child is higher. In this case, parents' concern is for efficiency more than equity. On the contrary, Behrman et al. (1982) suggest that parents will compensate for ability differences to achieve equality among children when parents' inequality aversion preferences outweigh efficiency concerns.

In response, a burgeoning empirical literature has examined the effect of child endowments on parental responses. However, the results of this literature are mixed, indicating overall either that there is no clear direction of parental response on child endowment, or that the response depends heavily on context. Some studies have found evidence of reinforcing parental responses (Aizer and Cunha 2012; Adhvaryu and Nyshadham 2016; Behrman et al. 1994; Datar et al. 2010; Frijters et al. 2013; Grätz and Torche 2016; Hsin 2012; Rosales-Rueda 2014); some have found compensating parental responses (Behrman et al. 1982; Bharadwaj et al. 2018; Cabrera-Hernandez 2016; Del Bono et al. 2012; Frijters et al. 2009; Griliches 1979; Halla et al. 2014; Leight 2017); some have found mixed responses (Ayalew 2005; Hsin 2012; Restrepo 2016; Yi et al. 2015); some have found no effect at all (Abufhele et al. 2017; Almond and Currie 2011).

Many of the recent empirical studies have relied heavily on the variation in birth weight to answer the question of parental responses, using a sibling fixed-effects (FE) model (Abufhele et al. 2017; Bharadwaj et al. 2018; Del Bono et al. 2012; Cabrera-Hernandez 2016; Datar et al. 2010; Hsin 2012; Restrepo 2016; RosalesRueda 2014). However, some studies argue that birth weight might be associated with prenatal endogenous input, and hence exploit a source of exogenous variation in the 
endowment at birth. Halla et al. (2014) study the effect of an exogenous shock on the Austrian 1986 cohort, who experienced a prenatal exposure to radioactive fallout from the Chernobyl accident. The shock decreases the birth weight, live births and Apgar score; and increases premature births and days for maternity leave. They find robust empirical evidence that parents compensate the children for experiencing input shocks. Adhvaryu and Nyshadham (2016) exploit variation in a plausible random in utero exposure to an iodine supplementation programme in Tanzania, and show that parents choose reinforcing investment in higher-ability children. Using Norwegian administrative data, Nicoletti et al. (2018) find that mothers compensate for low child birth weight by reducing maternal labour supply 2 years after birth. They instrument child birth weight by father's health endowment at birth, which arguably only brings variation in birth weight of child through genetic transmission without a direct impact on the mother's postnatal investments when conditioning on parental human capital and prenatal investments.

Meanwhile, other studies tackle this problem by using within-twins differences as a exogenous source of variation in endowment since prenatal parental investment is impossible to vary (Abufhele et al. 2017; Bharadwaj et al. 2018; Yi et al. 2015; Grätz and Torche 2016). For example, Abufhele et al. (2017) find that parents are neutral to the difference in birth weight of twins in Chile and support the existing evidence that parents do not invest differentially between twins. Using the same data, Bharadwaj et al. (2018) find similar results that parents do not invest differentially within twins, while, using a sample of parents with singleton siblings, compensatory behaviour is found. As Almond and Mazumder (2013) noted, the reason could be that it might be especially costly for parents to implement differential treatment between twins.

Important concerns about using twins as an instrument have been raised. Using individual data in 72 countries, Bhalotra and Clarke (2018) find that the distribution of twins is not random in the population and that indicators of the mother's health and health-related behaviours and exposures are systematically positively associated with the probability of a twin birth. Certainly, twins are not a large proportion of the population, and may be seen more as a special case.

We build on two recent studies that examine the effect of child endowment on parental investment and, rather than relying on twins data, use instrumental variables to alleviate concerns of endogeneity bias resulting from both unobserved household heterogeneity and child-specific heterogeneity. Using sibling differences in handedness as an instrument for cognitive ability differences, Frijters et al. (2013) find reinforcing behaviours of parents who are more likely to allocate more cognitive resources on an advantaged child in the USA. Grätz and Torche (2016), however, argue that handedness might vary over time so that it might not be an adequate instrument for child's early ability. Using the same technique but using variation in grain yields during the early life period of siblings as an instrument for physical health, Leight (2017) shows that Chinese parents invest more cognitive resources in the less-healthy child (as proxied by height-for-age) in Gansu province.

We combine a sibling-difference approach with instrumental variables, using the quasi-exogenous rainfall shocks occurring during the critical developmental period 
of a child as an instrument for differences in child ability between siblings. ${ }^{2}$ As studies find that rainfall shocks have a substantial impact on child development in agricultural contexts (see Almond et al. (2018) for a review), we exploit differences between siblings by looking at rainfall shocks from in utero during the first 3 years of their life $\mathrm{e}^{3}$ as a source of exogenous variation in nutritional inputs during the critical development period experienced by the siblings. ${ }^{4}$ Glewwe et al. (2001) note that a suitable instrument to capture within-sibling differences should be "(i) of sufficient magnitude and persistence to affect a child's stature; (ii) sufficiently variable across households; and (iii) sufficiently transitory not to affect the sibling's stature" (p. 350). We provide robustness checks in this paper to argue that rainfall shock timing does indeed provide a plausible source of exogenous variation.

To our knowledge, there are two other studies examining the pattern of parental investment in the context of Ethiopia. Ayalew (2005) examines catch-up growth of children in the dimensions of health and cognitive ability, using the first three rounds of the Ethiopia Rural Household Survey from 1994-1995. He finds compensating behaviour in health but reinforcing behaviour in cognitive skills. Arguably, the results for cognitive skills are less persuasive, since they use information on only one village in the survey. ${ }^{5}$ Second, using the Young Lives Older Cohort data and relying on ordinary least squares (OLS) and fixed-effects (FE) estimations for identification, Dendir (2014) finds reinforcing behaviours, proxying parental investment with enrolment and child time allocation and measuring ability using raw Peabody Picture Vocabulary Test (PPVT) scores ${ }^{6}$. Although the fixed-effects estimation successfully deals with the endogeneity issue caused by unobserved household characteristics, there is a potential high degree of correlation between child ability and unobserved child heterogeneity, such as parental preferences over one particular child, which is an individual effect. Dendir (2014) measured PPVT scores at adolescence (ages 12 and 15), which increases the probability that this measure of ability is contaminated by unobserved child characteristics and consequently biases the results, and therefore exogenous variation in cognitive ability is necessary for more plausible estimation.

While most of the existing literature reveals how parents respond to the difference in health within siblings, to the best of our knowledge, only the two studies discussed above (Ayalew 2005; Frijters et al. 2013) have examined differences in cognitive ability, and both have limitations. As it is of interest to show the specific parental response

\footnotetext{
${ }^{2}$ Rainfall information is external data matched with location by the Young Lives survey since the residence of interviewees is confidential.

${ }^{3}$ The period during pregnancy and the first 1000 days of life is widely recognised as the critical developmental period of child development (Doyle et al. 2009; Victora et al. 2010).

${ }^{4}$ Hill and Porter (2017) find that droughts cause a reduction in consumption of households in both rural and urban areas in Ethiopia.

${ }^{5}$ The outcome measure used is Ravens's Progressive Matrices scores, which did not work successfully in the Ethiopian context during Young Lives (Cueto and Leon 2012) as children were unable to understand the task.

${ }^{6}$ We discuss a better measure of ability and parental investment in Section 3.
} 
to one dimension of human capital, one would ideally like to disentangle the effect of investment in that particular dimension of human capital. However, constrained by data, only a few empirical studies have specific measures of investment in different dimensions, while most of the existing studies use a general measure of parental investment, such as time spent with the child. Yi et al. (2015)'s theory predicts that given the same early health shock, parents respond differently along different dimensions of human capital. The data they use contain detailed information on investment in family health and education. Yi et al. (2015) find mixed results: while parents compensate for the harmful effect of an early health shock by devoting more health resources to the worse-health child, they reinforce in the domain of cognition by allocating fewer educational resources to the disadvantaged child. Restrepo (2016) and Rosales-Rueda (2014) use the same dataset from the USA, the National Longitudinal Survey of Youth-Children 1979 (NLSY-C79), which gives information on inputs of time and goods in either cognitive or socio-emotional development. They suggest that parents tend to simultaneously reinforce the effect of low birth weight by providing less cognitive stimulation and emotional support to the low-birth-weight child. In our study, we measure direct cognitive investment using total expenditure on educational fees at the individual child level.

Most existing research attempts to examine parental responses to child endowments on average. Some sociological studies emphasise that in theory, socioeconomic heterogeneity should be taken into account, specifically, the degree and direction of parental responses might vary by family socio-economic status (SES) (Lareau 2011; Lynch and Brooks 2013). Some consider that lower-class parents have difficulty in affording costly and risky investment in disadvantaged children, and would be more likely to reinforce differences in ability. Higher-class parents tend to be averse to inequity so may compensate for a low ability outcome (Conley 2008). On the contrary, others suggest that high-SES families may reinforce gaps in child ability by providing more educational investment to the advantaged child, while offering direct transfers, such as gifts or bequests, to the disadvantaged child (Becker and Tomes 1976; Becker 1991).

To date, only a small number of empirical studies have looked at variation in parental responses by SES, though these are all in a developed country context. Grätz and Torche (2016) find out that advantaged parents allocate more cognitive stimulation to higher-ability children, while disadvantaged parents behave indifferently to ability gaps. Yet, Halla et al. (2014) show that families with low socio-economic status chose to give birth to fewer children when their children experienced the Chernobyl accident; similarly, families with high socio-economic status compensate their low-endowed children by supplying less maternal labour (and investing more in childcare). Hsin (2012) uses maternal educational level to measure family socioeconomic status. On average, no compensating or reinforcing investment is found for low-birth-weight outcomes. However, low-educated mothers prefer reinforcing investment by spending more time with heavier-birth-weight children at 6 years old, while high-educated mothers compensate low-birth-weight children by spending more time with them. Restrepo (2016) finds reinforcing behaviour on average, with low-SES families reinforcing the differences in birth weight with a greater amount of investment compared with high-SES families. None of these studies provide evidence 
in the context of developing countries, except Cabrera-Hernandez (2016) who finds that high-educated mothers in Mexico compensate for the low-birth-weight outcome by offering more school expenditure to the disadvantaged child.

\section{Data and measures}

Young Lives is an international longitudinal study of 12,000 children growing up in four developing countries (Ethiopia, India, Peru and Vietnam) over 15 years (Barnett et al. 2012), examining the causes and consequences of childhood poverty. The main cohort (2000 children in each country) were born within 12 months of each other in 2001. An older cohort (1000 children in each country) born 7 years earlier is used as a comparison group. This paper uses data from four rounds of the Ethiopia survey, focusing on the Younger Cohort (YC) and their siblings. Round 1 was conducted in 2002 (when YC index children were, on average, 1 year old), round 2 in 2006 (approximately age 5), round 3 in 2009 (approximately age 8) and round 4 in 2013 (approximately age 12). In rounds 3 and 4, one sibling, closest in age to the YC index child (either younger or older), was interviewed. This brings variation in that $\mathrm{YC}$ index children could be either born earlier or later in our analysis. ${ }^{7}$

To reduce heterogeneity in child activities and parental investment, we confine the sample of YC index children ${ }^{8}$ and their siblings to be aged from 7 to 14 in round 4 , being old enough to enter primary school and young enough to stay in the primary school in Ethiopia. The sample is reduced to 701 sibling pairs (1402 observations) in the sibling-difference specification, born from 1998 to 2006.

\subsection{Rainfall}

We use monthly rainfall data at the community level additionally provided to us by Young Lives, which we merge with the survey data using birth year, birth month and birthplace (from round 1 and round 2 survey), in order to generate instrumental variables at the child-specific level. Annual rainfall is measured for each child from the 12 months prior to the birth month, so that the rainfall shock varies monthly and yearly. We use standardised annual rainfall from in utero, the first, second and third years of the child's life in the birthplace of the child as instrumental variable, following the literature arguing that this is the critical developmental period (Almond et al. 2018). During this period, adequate rainfall contributes to improved income for the household and therefore translates into a positive nutritional input for child ability (Maccini and Yang 2009). The mean and standard deviation are calculated at the birth community level using rainfall from 1985 to 2008. In the context of Ethiopia, an extremely drought-prone agricultural country, we hypothesise that the more rainfall during the critical development period, the higher the child's ability (Dercon and Porter 2014).

\footnotetext{
${ }^{7}$ There are 610 YC index children older than their surveyed siblings, and 91 who are younger. The average age difference in month is 27 months. See Table 1 for details.

${ }^{8}$ In the following, we will describe YC index children as "index children" for simplicity.
} 


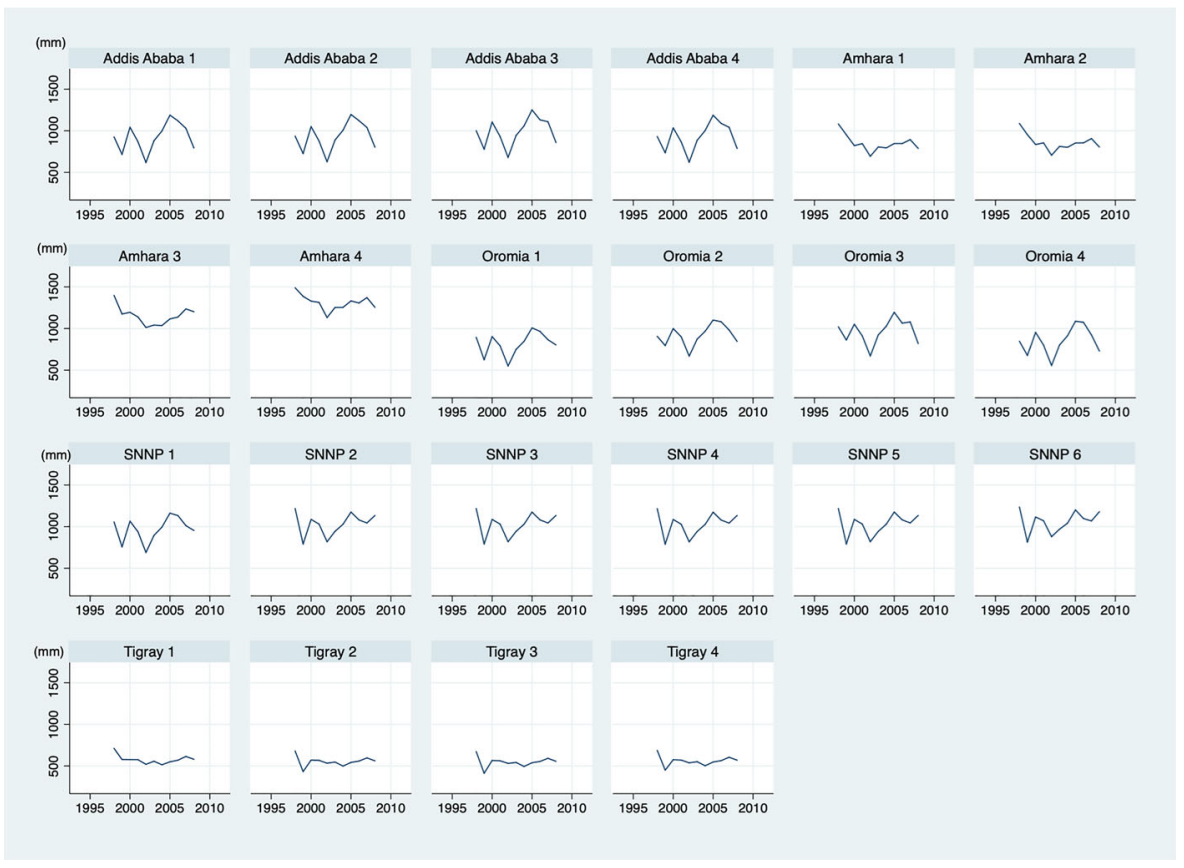

Fig. 1 Annual rainfall by community, 1998-2008

Since the sibling pairs in our sample are mainly born in the same community, the variation in the child-specific instrument variable relies on the time dimension, namely the birth month and birth year. ${ }^{9}$ As the sibling pairs in the sample are born between 1998 and 2006, we check the distribution of annual rainfall in each community during the period from 1998 to 2008 (i.e. the second of year of life for a child born in 2006). Figure 1 shows that rainfall in most of the communities is volatile, characterised by two severe droughts in 1999 and 2002 in Ethiopia. As 90\% of the sibling pairs in our sample are born at least 2 years apart, the correlation of the rainfall instrumenting for each child ability is arguably weak. ${ }^{10}$ Furthermore, we carry out a series of $t$ tests to examine the difference in rainfall that sibling pairs experience in their early life respectively and find that the annual rainfall during the critical developmental period between index child and the sibling is statistically different. Specifically, the index child is reported to be exposed to a statistically lower level of rainfall as they are mostly born during 2001 and 2002, when drought hit Ethiopia.

\footnotetext{
${ }^{9}$ Three per cent of the sample were born in different communities due to migration: we include these and controls for community fixed effects. The results are robust excluding this 3\%, shown in Table 6 row 7 .

${ }^{10} \mathrm{We}$ acknowledge that as a cohort study, half of the index children in our sample are born within 12 months of one another, and therefore if any policy or other shock which is correlated with rainfall happened during the birth period, then results may be influenced by such an unobserved cohort effect. However, examining the community data files from the Young Lives survey we did not find any such event.
} 

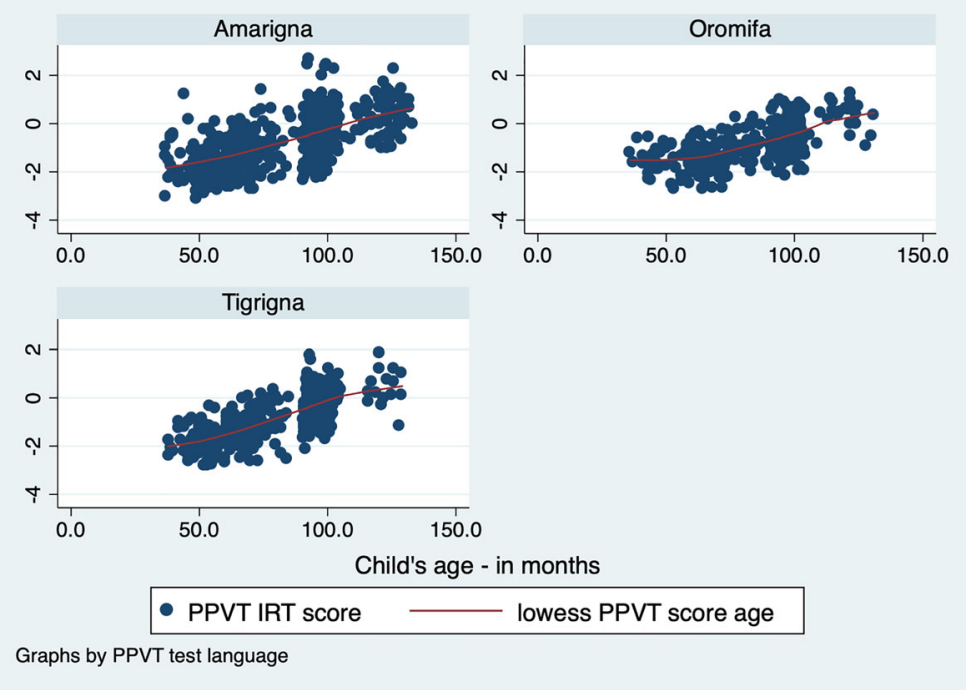

Fig. 2 IRT PPVT scores by language, 2009

\subsection{PPVT scores as a measure of cognitive ability}

To analyse the effect of children's cognitive ability on within-household allocation of cognitive resources, our main independent variable of interest is the child's cognitive ability in 2009 (round 3). The Peabody Picture Vocabulary Test (PPVT) is a receptive vocabulary test designed by Dunn and Dunn (1997), a consistent test measuring cognition ability for both index children and siblings in Young Lives. Therefore, we measure the child's cognitive ability using this metric. ${ }^{11}$ The PPVT is a widely used test to measure verbal ability and general cognitive development (see Crookston et al. (2013); Paxson and Schady (2007)), and the PPVT test score is positively correlated with other common measures of intelligence such as the Wechsler and McCarthy Scales (Campbell 1998). Given that round 3 is the first round that has information on siblings, our analysis only uses the latter two available rounds of the Young Lives data.

Given the difficulty of comparing raw PPVT scores across different rounds of data collection as children age, we employ item response theory (IRT) to standardise cognitive measures by language, following Leon and Singh (2017). ${ }^{12}$ Figure 2 shows ${ }^{13}$ that the IRT PPVT scores increase along with age, yet the means of IRT PPVT scores vary by language, consistent with findings of Leon and Singh (2017)

\footnotetext{
${ }^{11}$ In the Young Lives study, there are two other cognitive tests, the Early Grade Reading Assessment (EGRA) and a maths test. However, they are only available for index children, not for siblings.

${ }^{12}$ See Leon and Singh (2017) for further details. We exploit the item parameters for each language calculated by Leon and Singh (2017) to generate IRT scores of children in Round 3. We use Stata command openirt programmed by Tristan Zajonc.

${ }^{13}$ Scatterplots and locally smoothed regression lines using the 'lowess' command in STATA 13.
} 


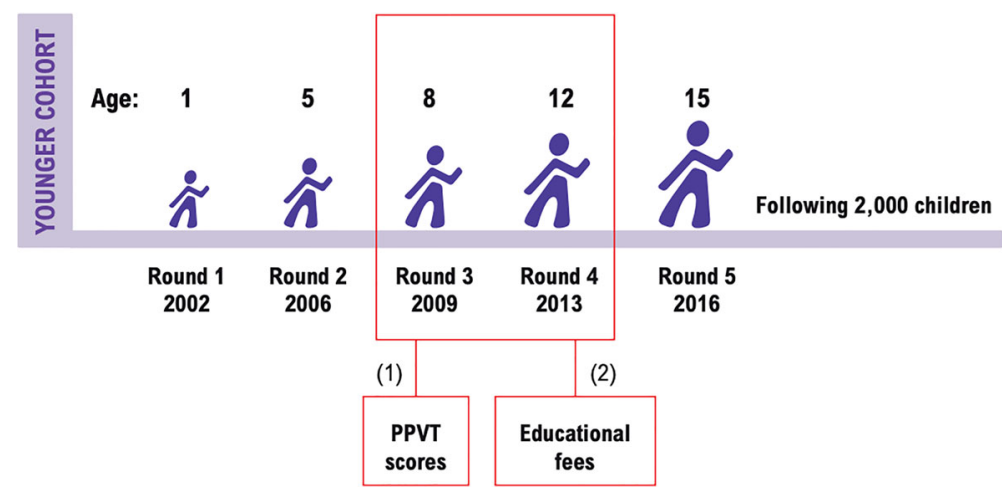

Fig. 3 Young Lives survey timings

(Tigrigna is the highest, followed by Amarigna and Oramifa). To ease the interpretation of subsequent estimation results, and given that is is not advisable to compare across languages (Cueto and Leon 2012), the IRT scores have been standardised by language as our measure of cognitive ability, with a mean of 0 and a standard deviation of 1 .

\subsection{Total educational fees as a measure of cognitive resources}

Our dependent variable is the allocation of parental cognitive resources, measured by the total educational fees paid in 2013 (round 4) per child. As Fig. 3 shows, an advantage of our panel data is that it leaves a longer period of time (4 years between round 3 and round 4) to measure potential parental responses after children are assessed by PPVT in round 3, while prior research mostly relies on the parental involvement measured quite soon after child ability is observed. The total educational fees are the sum of school fees and private tuition fees, serving as a direct measurement of cognitive investment.

To alleviate the concern that public educational investment and private tuition investment are substitute goods, we use Pearson's correlation ${ }^{14}$ to test the strength and direction of the association between these two continuous variables. While the Pearson correlation coefficient between the school fees and tuition fees, $r=0.732$ at $95 \%$ confidence level, suggests that in the pooled sample higher school fees are related to higher tuition fees, the correlation coefficient estimating the association between school fees and tuition fees within-family $(r=-0.020)$ is statistically nonsignificant at $95 \%$ confidence level. This lack of correlation leads us to use total educational fees as the dependent variable of our main analysis. ${ }^{15}$

Figure 4 shows how total educational fees are reported. In the pooled sample, shown by the left-hand chart, $76 \%$ of parents report zero total educational fees in

\footnotetext{
${ }^{14}$ We use Stata command pwcorr to carry out Pearson's correlation test.

15 We provide analysis using private tuition fees as the dependent variable in the robustness check. See Table 6.
} 

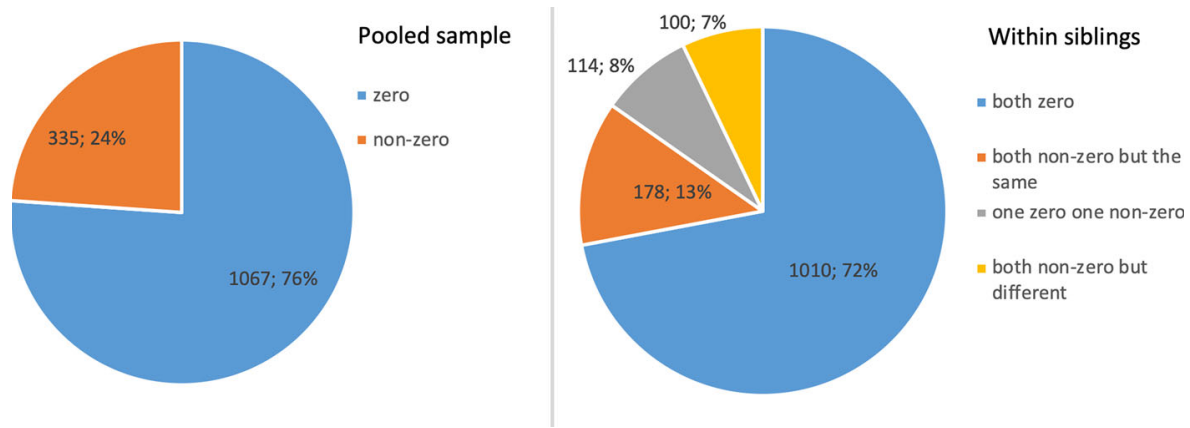

Fig. 4 Total educational fees

Ethiopia, while $24 \%$ report non-zero educational fees. ${ }^{16}$ Looking at the allocation between siblings, indicated by the right-hand chart, $16 \%$ of parents differentiate their financial educational resources among their children, while $13 \%$ of parents allocate financial resources to child education and adopt no differentiating strategy in investing their children. Our interest is to find out whether the parental investing strategy of those who invest financial resources in their children is responsive to the difference in cognitive ability.

School fees and private tuition fees as a proxy of cognitive resources are specifically documented in parents' answers to the questions such as 'how much you spend on school (private tuition) fees per year?'. For the sake of interpretation, we standardise the total educational fees for the analysis.

To understand whether parents report a higher level of investment for the index children, we perform a $t$ test on the total educational fees between index children and their siblings. The $t$ statistics $(=0.132)$ shows that the difference in investment between two children is not statistically different, suggesting that parents do not deliberately report a higher investment for the index children.

Figure 5 shows the raw correlation between mean cognitive ability and mean cognitive resources for each 5 percentile for the included sample. Despite the flat relationship on the left tail of the distribution, the aggregate correlation between ability and parental investment is positive in the cross-section OLS estimation. Our interest is to find out whether this plausible positive relationship continues to hold when we apply our empirical methods accounting for child observable and unobservable factors.

Therefore, we include a series of child observable characteristics as confounding factors. First, to alleviate the concern that the cognitive investments are age-related, we control for several age-related factors in the regression analysis. We make use

\footnotetext{
${ }^{16}$ Our sample also includes those who are at school age but not enrolled currently (121 children). We assign zero educational fees to them. The high percentage of zero educational fees is also due to the abolition of school fees in public schools for grades 1 to 10 in Ethiopia in 1994. However, hidden costs remain (Oumer 2009). UNICEF (2009) find that there were still payments in various forms in government schools after the policy of abolishing school fees. According to the Policy and Human Resource Development (PHRD) study, on average, a government school was levying about Birr 10 to 15 per year per student.
} 


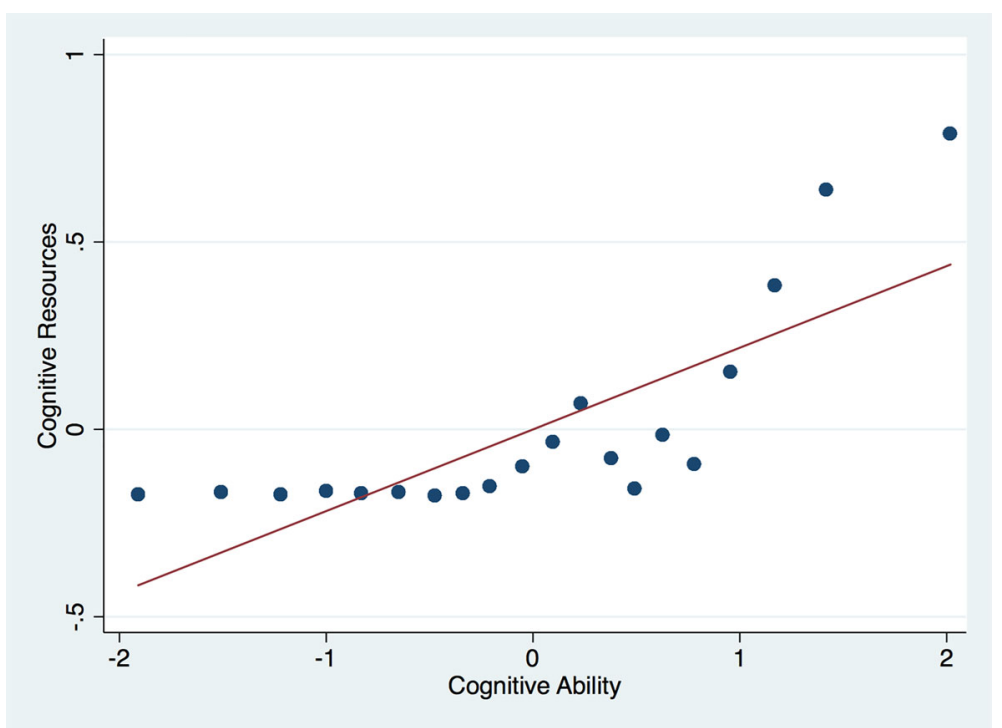

Fig. 5 Mean cognitive resources and cognitive ability for each fifth percentile of the cognitive ability distribution

of age in months, together with square and cube of age in months and dummies of birth year. Then, since evidence suggests that children born earlier receive the greater investment (Price 2008; Buckles and Kolka 2014), we control for birth order. Other child-level differences which might contribute to investment variation are also controlled for in the regression analysis. Specifically, maternal age at birth, heightfor-age $Z$-score (HAZ) in round 3, birthplace, birth quarter and type of siblings (e.g. born as an older brother with a younger sister, or born as an older sister with a younger brother) are taken into account. ${ }^{17}$ See Table 1 for summary statistics.

\subsection{Socio-economic status}

To understand whether educational investment varies by socio-economic status (SES), we carry out several exploratory $t$ tests and find that families investing in education are indeed the high-SES families. The families who make positive investments in child education are significantly richer $(t=-12.253)$, with a significantly better educated mother $(t=-9.749)$ and smaller size $(t=-3.991)$. In order to

\footnotetext{
${ }^{17}$ There are eight factor variables to denote the type of siblings: born as an older brother with a younger sister, born as younger sister with a older brother, born as an older sister with a younger brother, born as a younger brother with a older sister, born as an older brother with a younger brother, born as younger brother with a older brother, born as an older sister with a younger sister, born as a younger sister with a older sister. When we use our fixed-effects strategy, many are dropped due to their multicollinear relationship when the information of index children is deducted by their siblings'. Note that we only include time-varying household characteristics due to our sibling difference specification.
} 
Table 1 Summary statistics

\begin{tabular}{|c|c|c|c|c|}
\hline Variable & Mean & $\mathrm{SD}$ & Mean (within) & SD (within) \\
\hline \multicolumn{5}{|l|}{ Cognitive resources } \\
\hline Total educational fees (standardised) & 0.000 & 1.000 & -0.007 & 0.054 \\
\hline \multicolumn{5}{|l|}{ Cognitive ability } \\
\hline PPVT scores (standardised) & 0.000 & 1.000 & -0.867 & 0.891 \\
\hline \multicolumn{5}{|l|}{ Child characteristics } \\
\hline Age in months & 131.758 & 21.263 & -26.765 & 23.184 \\
\hline Maternal age in months at birth & 27.370 & 6.064 & 2.215 & 1.952 \\
\hline Birth order & 3.490 & 1.858 & 0.743 & 0.682 \\
\hline Born as an older sister with a younger brother $(\mathrm{dv})$ & 0.118 & 0.322 & -0.173 & 0.454 \\
\hline Born as an older brother with a younger sister $(\mathrm{dv})$ & 0.135 & 0.342 & -0.218 & 0.471 \\
\hline Born as an older brother with a younger brother (dv) & 0.130 & 0.336 & -0.211 & 0.464 \\
\hline Born as an older sister with a younger sister (dv) & 0.118 & 0.322 & -0.138 & 0.465 \\
\hline Born as a younger brother with an older sister (dv) & 0.130 & 0.336 & 0.211 & 0.464 \\
\hline Born as a younger sister with an older brother $(\mathrm{dv})$ & 0.118 & 0.322 & 0.138 & 0.465 \\
\hline Born as a younger brother with an older brother (dv) & 0.118 & 0.322 & 0.173 & 0.454 \\
\hline Born as a younger sister with an older sister (dv) & 0.135 & 0.342 & 0.218 & 0.471 \\
\hline HAZ in round 3 & -1.359 & 1.129 & -0.141 & 1.233 \\
\hline Birth quarter $1(\mathrm{dv})$ & 0.213 & 0.410 & 0.013 & 0.577 \\
\hline Birth quarter $2(\mathrm{dv})$ & 0.295 & 0.456 & -0.054 & 0.646 \\
\hline Birth quarter $3(\mathrm{dv})$ & 0.216 & 0.412 & 0.021 & 0.608 \\
\hline Birth quarter $4(\mathrm{dv})$ & 0.275 & 0.447 & 0.020 & 0.618 \\
\hline Rainfall in utero (standardised) & 0.075 & 0.901 & -0.497 & 1.210 \\
\hline Rainfall at birth (standardised) & -0.449 & 1.039 & 1.225 & 1.440 \\
\hline Rainfall in year 1 (standardised) & -0.155 & 0.796 & 0.924 & 0.997 \\
\hline Rainfall in year 2 (standardised) & -0.055 & 0.704 & 0.307 & 0.956 \\
\hline \multicolumn{5}{|l|}{ Household characteristics } \\
\hline Wealth index & 0.348 & 0.164 & 0.000 & 0.000 \\
\hline Mother with education (dv) & 0.459 & 0.499 & 0.000 & 0.000 \\
\hline Household size & 6.522 & 1.646 & 0.000 & 0.000 \\
\hline$N$ & 1402 & & & \\
\hline
\end{tabular}

$d v$, dummy variables; within, data constructed in 'within-family' structure

further investigate whether these better-off families who invest in education differentiate their investment based on the ability gap between their children, we stratify our analysis on parental responses. Specifically, we employ several household characteristics (maternal education, family wealth and household size) as indicators of family SES, while we dichotomise each indicator generating a high-SES group and a lowSES group following Grätz and Torche (2016). With regard to maternal education, in fact, half of the mothers in our sample are not educated at all, so that we distinguish 

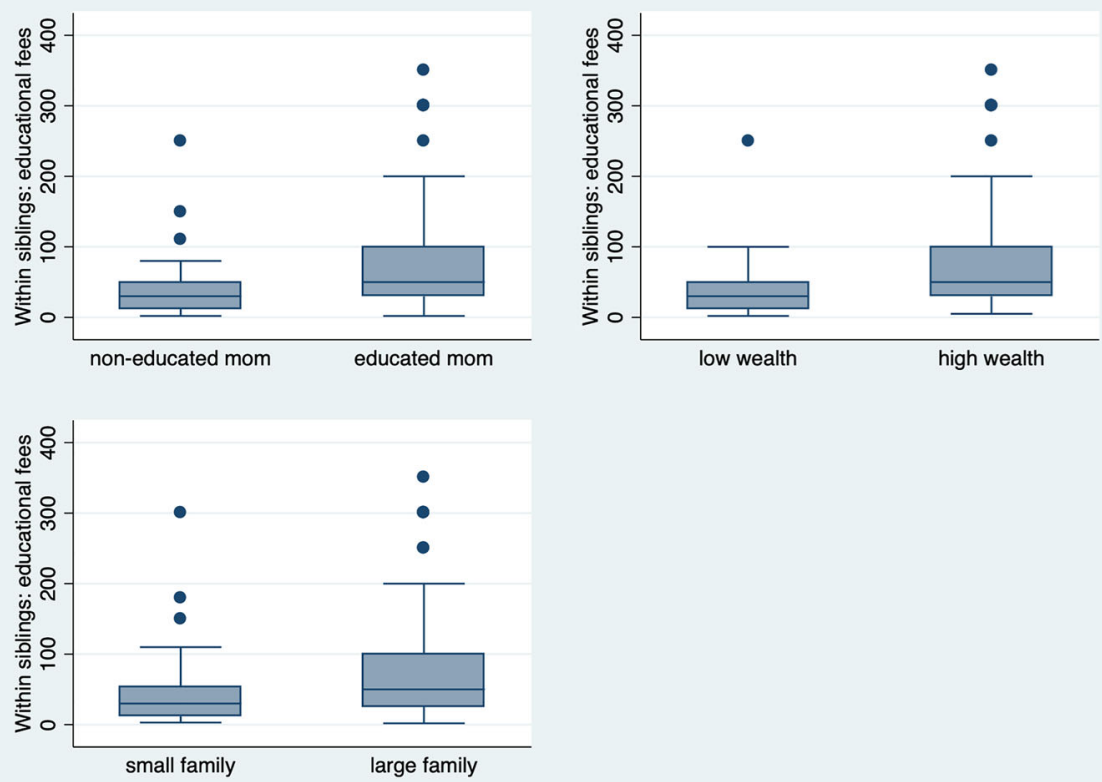

Fig. 6 Intrahousehold difference in total educational fees by SES

between families with an educated mother or a non-educated mother. In the case of family wealth and household size, we dichotomise them using the median of wealth index and size of the family. ${ }^{18}$

Figure 6 shows the intrahousehold difference in total educational fees by SES. The distributions of within-sibling difference in educational fees are similar across three indicators. In general, the high-SES families have bigger differences in allocating educational resources among their offspring. The mean of the difference in total educational fees in low-SES families is small but non-zero.

\section{Econometric strategy}

To identify the causal effect of cognitive ability on parental investment, the analysis is based on an IV-FE model, targeting three main endogeneity threats. First, this approach relates within-sibling pair differences in ability in 2009 (round 3) with within-sibling pair differences in parental cognitive investment 4 years later in 2013 (round 4) to address the threat of reverse causality. Second, the sibling fixedeffects (FE) models control for unobserved heterogeneity at the household level,

\footnotetext{
${ }^{18}$ The wealth index is the average of housing quality index, consumer durable index and housing service quality index.
} 
following most existing empirical works. Third, we use instrumental variables to isolate the exogenous variation in child ability, addressing endogeneity resulting from unobserved child heterogeneity.

The sibling fixed-effects structural model can be written as follows:

$$
\Delta I_{h}=\beta \Delta C A_{h}+\Delta X_{h} \Lambda+\Delta \epsilon_{h},
$$

where $\Delta I_{h}$ is the difference in cognitive investment between siblings in family $h$ in round 4 (i.e. total educational fees), $\Delta C A_{h}$ is the difference in ability between siblings in round $3, \Delta X_{h}$ is a vector of differences in other characteristics between siblings (e.g. child's age, maternal age at birth, height-for-age in round 3 , birthplace, birth quarter, birth year, birth order, type of sibling pairs-gender of older and younger child) and $\Delta \epsilon_{h}$ is the difference of the idiosyncratic error term between siblings. In this estimation, time-invariant household observable characteristics and household unobservable confounding factors are purged from the specification, but unobserved child heterogeneity, such as personality, remains.

As noted above, we overcome endogeneity bias resulting from unobserved child heterogeneity, with an instrumental variables (IV) estimation procedure. The firststage equation is:

$$
\Delta C A_{h}=\sigma \Delta R_{h}+\Delta X_{h} \Omega+\Delta \mu_{h},
$$

where $\Delta R_{h}$ is the difference in rainfall shock from in utero to the first 3 years of a child's life between siblings as a source of exogenous variation in nutritional inputs experienced by the siblings, and $\Delta \mu_{h}$ is a random error term in the first stage.

The IV approach is also helpful in the sense of overcoming attenuation bias related to measurement error in cognitive ability. Even if we consider the PPVT test score a good proxy for ability observed by parents, there is still likely to be measurement error in the test, and in its relation to parental perception of ability. For example, parents may have some other perception of their children's cognitive ability than the PPVT score. This potential problem of measurement error can be solved by our IV approach if it is classical. Indeed, in a sibling FE model, attenuation bias caused by measurement error is augmented if one's analysis moves from a cross-sectional setting to a FE setting (Bound and Solon 1999).

The sibling FE model coupled with the IV strategy helps us interpret $\beta$ as the Local Average Treatment Effect of change in parental cognitive investment caused by the variation in child cognitive ability, which is driven by the exogenous variation in rainfall during the critical developmental period of the two children. We note that the monotonicity assumption applies to LATE estimates (Angrist and Pischke 2008), that for an change in rainfall, there should be a monotonic increase in 'treatment' intensity. If $\beta>0$, parental investment increases with relative ability. Parents reinforce the differences in ability by allocating more resources to the high-ability child. If $\beta<0$, it means parents compensate for the difference in ability, allocating more resources to the low-ability child.

Under the assumption of higher marginal returns to investment in higher-ability children, the case of $\beta>0$ also implies that parents are concerned more with the efficiency of investment and try to maximise their children's total future wealth. The case of $\beta<0$, on the other hand, implies that when equity outweighs efficiency, parents forgo maximising returns from educational investment, trying to achieve higher 
equity among children. Del Bono et al. (2012) note also that there may also be a 'pure endowment effect', whereby if marginal utility of parents with respect to any individual child's ability is positive but decreasing (i.e. the second derivative of the utility function is negative), then higher endowment of that child effectively increases family resources, but these can only be released by decreasing investment in that child. This effect is then expected to operate in the same direction as the equity effect.

We report two types of standard errors: one robust to general heteroskadasticity and the other one robust to within community dependence. ${ }^{19}$

\section{Results}

In order to test the relationship between cognitive ability and deployed cognitive resources, we regress parental cognitive resource allocation in primary school on cognitive ability observed one period earlier. In all of the estimation results, total educational fees paid for each child is the proxy for cognitive resources, while PPVT scores are the proxy for cognitive ability.

For each specification, we use the sample of children who have a surveyed sibling and the information for both siblings is available. Furthermore, we have restricted the sibling-pairs to be of primary school age and use the same language in PPVT test. A set of child-level covariates is included in all models, such as age in months, maternal age at birth, height-for-age in round 3, birthplace, birth quarter, birth order, type of sibling pairs and birth year.

\subsection{Preliminary results}

Table 2 presents the preliminary results from the OLS models and FE model. The inconsistency of the estimates from these models is evident, the magnitudes and signs of which are not stable as we add additional controls, suggesting severe endogeneity of the variable of interest. For example, the cross-sectional OLS estimate reported in column 1, when only child-level controls are included in the model, suggests a positive relationship between ability and total educational fees. However, when we include household-level traits, maternal educational background and regional fixedeffects in the model, the point estimate decreases from 0.133 to 0.059 .

However, the OLS estimate is still likely to be biased due to unobserved characteristics within the family, such as genetically innate ability, parental preferences for child quality and budget constraints. Hence, we exploit the sibling FE model, using a similar strategy to Bharadwaj et al. (2018), Datar et al. (2010) and Hsin (2012) studying parental responses to birth weight, controlling for unobserved household-level characteristics. In column 5 of Table 2, the FE estimate suggests a negative association between ability and investment, although it is not statistically significant. Aside from this, endogeneity bias might still persist since the cognitive ability is postnatal

\footnotetext{
${ }^{19}$ There are 46 clusters in the sample.
} 
Table 2 Preliminary regression models

\begin{tabular}{llllll}
\hline $\begin{array}{l}\text { Dependent variable: } \\
\text { total educational fees }\end{array}$ & OLS & OLS & OLS & OLS & FE \\
\hline Cognitive ability & $(1)$ & $(2)$ & $(3)$ & $(4)$ & $(5)$ \\
\hline Child-level controls & $0.133^{* *}$ & $0.076^{*}$ & $0.064^{* *}$ & $0.059^{* *}$ & -0.002 \\
Household-level controls & $(0.060)$ & $(0.041)$ & $(0.032)$ & $(0.029)$ & $(0.004)$ \\
Mother-level controls & Yes & Yes & Yes & Yes & Yes \\
Region fixed effects & - & Yes & Yes & Yes & Yes \\
Sibling fixed effects & - & - & Yes & Yes & Yes \\
Observations & 1402 & 1402 & 1402 & 1402 & Yes \\
\hline
\end{tabular}

Community clustered standard errors are in parentheses. * $p<0.10$, ** $p<0.05$, *** $p<0.01$. The dependent variable is total educational fees. Children controls are age in months, square of age in months, cubic of age in months, maternal age at birth, gender, birthplace, birth quarter, birth order, birth year, height-for-age $Z$-score, language of tests and the type of sibling. Household-level controls are type of residential site, household size, wealth index and gender of household head. Mother-level controls are a series of levels of maternal education

and time-varying, which allows after-birth ability to embody a significant component of prior parental investment.

To address the bias, we isolate the exogenous variation in cognitive ability using quasi-exogenous variation in rainfall during the critical developmental period. Thus, we apply instrumental variable methods to the sibling fixed-effects approach (IVFE), a similar approach to Frijters et al. (2013) and Leight (2017), who use the same strategy but different instruments to ours.

\subsection{Main results}

\subsubsection{IV-FE models: first-stage results and diagnostics}

Before presenting our main IV-FE results, we discuss the first-stage results, as well as the underidentification and weak identification tests in Table 3. Specifically, in the first-stage estimations, endogenous cognitive ability is regressed on the exogenous regressors and excluded instruments (i.e. the rainfall during critical developmental period). We find that children who experienced relatively good rainfall aged 0-24 months have significantly higher test scores than their siblings in their early childhood; rainfall during infancy is relevant to cognitive ability as proxied by receptive vocabulary.

Shown in columns 1 to 4 in Table 3, we regress ability in childhood on annual rainfall from in utero to the first 3 years of child life respectively. We find that annual rainfall during 0 to 12 months of life and 13 to 24 months of life is significant. Therefore, we construct an IV using the average rainfall during 0 to 24 months of life and report the result in column 5 . The estimate is positive and statistically significant, with 


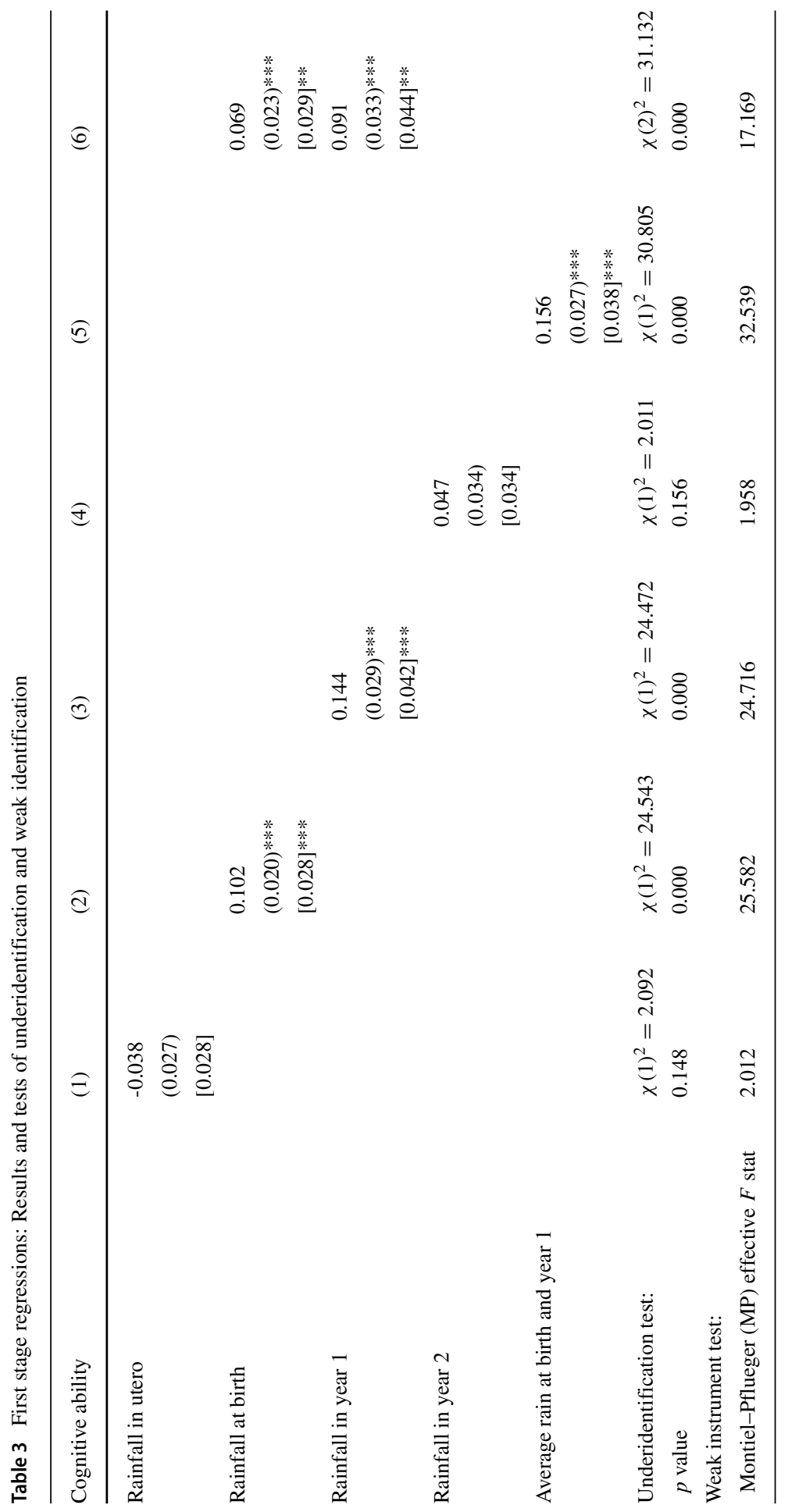




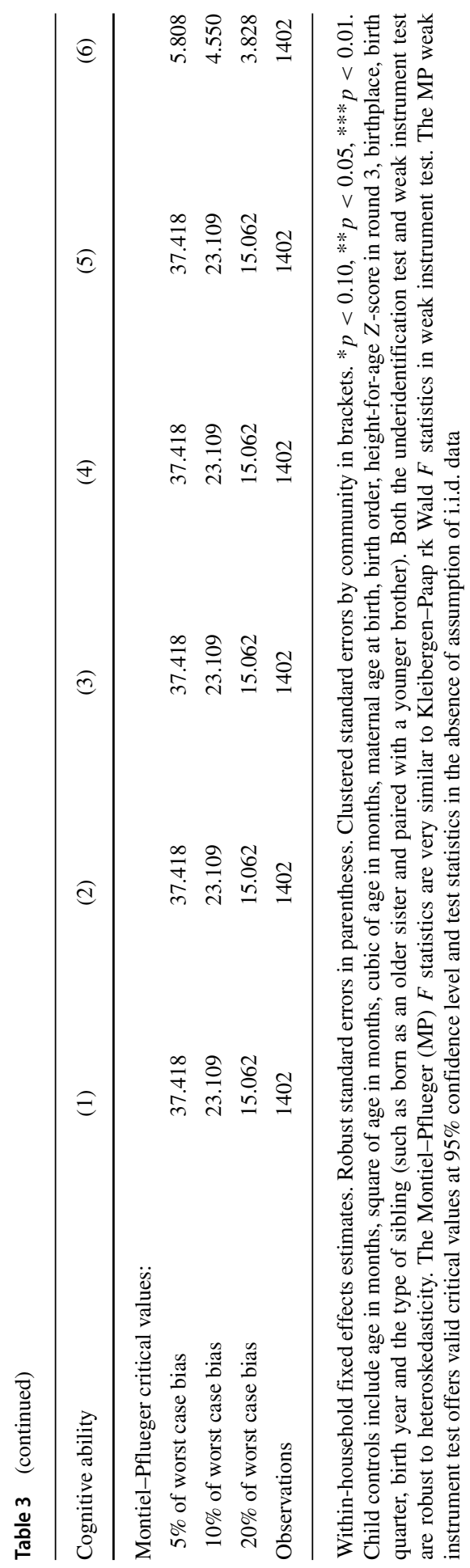


a $t$ statistic of 5.70, suggesting that an increase of one standard deviation in rainfall during the first 2 years of life is correlated with an increase of $15.6 \%$ of one standard deviation in cognitive ability in early childhood. In column 6 , when we include both the rainfall during the first year and the second year of life as IVs into the IV-FE model, both of the estimates are positive and statistically significant.

With regard to the underidentification tests, ${ }^{20}$ the $p$ values for the specifications 2 , 3, 5 and 6 all reject the hypothesis that the IV models are underidentified respectively, though not specifications 1 and 4, suggesting that the IV models are likely to be underidentified using either rainfall in utero (column 1) or rainfall in the third year of life (column 4) as the excluded instrument variable. Therefore, in the following, we focus on four IV-FE models: three of them are single IV models using rainfall from 0 to 12 months, rainfall from 13 to 24 months and average rainfall from 0 to 24 months; the last one is a two-IV model using both rainfall from 0 to 12 months and from 13 to 24 months.

We further examine the validity of the IVs by conducting a battery of weak identification tests. Noting that the traditional Cragg-Donald weak instrument test applies to the case of i.i.d. data only, we report a robust weak instrument test by Olea and Pflueger (2013) which gives valid test statistics Montiel-Plueger (M-P) effective $F$ statistics and Montiel-Plueger critical values in the existence of heteroskedasticity at 95\% confidence level. ${ }^{21}$ Although the robust M-P $F$ statistics in the specifications 2 and 3, which are 25.582 and 24.716, satisfy the 'rule of thumb' recommended by Staiger et al. (1997), when comparing them with the robust critical values given by M-P test, we notice that these statistics are slightly higher than the M-P critical value for a maximum IV bias of $10 \%$, suggesting that there is a $5 \%$ chance that the bias in the IV estimator is $10 \%$ of the worst case possible.

When we use average rainfall between the age of 0 to 24 months as the excluded instrument, the robust weak instrument test suggests that this IV is reasonably 'strong'. In column 5 in Table 3, the robust M-P $F$ statistic is 32.539 , which is sufficiently above the robust M-P critical value for a maximum IV bias of $10 \%$. Additionally, the combined sets of instruments in column 6 are also 'stronger' than the ones in columns 2 and 3, as its M-P F statistic is 17.169 which is higher than the critical value for a maximum IV bias of $5 \%$.

To conclude, the single instrument of average rainfall at the age from 0 to 24 months and combined set of instruments of rainfall at the age from 0 to 24 months are respectively relevant, implying the second-stage inferences will be valid and point estimates are only likely to include a relative bias lower than $10 \%$ at a $95 \%$ confidence level. These results could also serve as a supplement to the studies investigating whether some periods during the critical developmental period are more important.

\footnotetext{
${ }^{20}$ The underidentification test is an LM version of the Kleibergen and Paap (2006), which allows for non-i.i.d. errors.

${ }^{21}$ We use weakivtest programmed in Stata by Pflueger and Wang (2015). The Montiel-Plueger effective $F$ statistics are very close to the built-in Kleibergen-Paap rk Wald $F$ statistics in the programme xtivreg2 written by Schaffer et al. (2015). However, the robust critical values of the latter are not provided. Thus, we use the Montiel-Plueger critical values as thresholds in order to report the bias.
} 
We find that children are particularly vulnerable at the age of 0 to 24 months in developing cognitive ability in Ethiopia, which is consistent with the findings of Maccini and Yang (2009), though Dercon and Porter (2014) find children exposed to famine at the age of 12 to 36 months are shorter than their peers in Ethiopia. In Table 9, we show IV redundancy test of a specified IV, which supports the hypothesis that rainfall at the age from 0 to 24 months are not redundant.

\subsubsection{IV-FE models: second-stage results}

Our main estimation results are presented in Table 4, where the second-stage estimations using four IV models selected from above are presented. Across the four IV-FE models, the point estimates ${ }^{22}$ are significantly negative, suggesting a compensating behaviour when parents observe their child to be underdeveloped. Particularly, remembering that the preferred IVs used in specifications 5 and 6 in Table 3, whose corresponding results are shown in columns 3 and 4 in Table 4, are relatively more relevant, the point estimates of these two specifications are very close $(-0.038$ and -0.039). It suggests that an increase in cognitive ability of one standard deviation decreases cognitive resources by $3.8-3.9 \%$ of a standard deviation. ${ }^{23}$

The confidence intervals given by a set of weak identification tests ${ }^{24}$ are negative. Specifically, the Anderson-Rubin (AR) test gives negative confidence sets of estimated $\beta$ that is robust to potential bias introduced by weak instruments gives negative confidence intervals at a $90 \%$ confidence level. In the two-IV model, besides the AR test, the Moreira CLR test, $\mathrm{K}$ test and K-J test are available. The K-J test is more efficient than the AR test, and Moreira CLR test and K test obtain more power than AR test when the model is overidentified. Compared with $\mathrm{K}$ test, K-J test and Moreira CLR test do not suffer from spurious power losses (Finlay et al. 2016). While all of the AR, Moreira CLR, K and K-J tests give negative confidence sets, the latter three are almost identical, between $[-0.067,-0.023]$ at a $90 \%$ confidence level. The J test rejection probability is low everywhere except for very high values of $\beta$, suggesting that the instruments are exogenous.

To allay the concern of our proposed IV being possibly not perfectly exogenous, we further exploit a newly developed estimator by Conley et al. (2012), which identifies a threshold for the plausible estimate even if the IV is imperfect, i.e. the excluded instrument is directly correlated with the dependent variable. ${ }^{25}$ Specifically, one might worry that rainfall in infancy might have a direct impact on contemporaneous parental investment, despite our argument that the impact on household income is only contemporaneous and short-lived (Glewwe et al. 2001); another concern might be that early life rainfall would affect early life parental responses, which are

\footnotetext{
${ }^{22}$ The IV-FE point estimates are given by xtivreg2 programmed by Schaffer et al. (2015).

23 The mean of the total educational fees is 123.23 Birr.

${ }^{24}$ The AR, Moreira CLR, K, J and K-J confidence intervals are given by weakiv, programmed by Finlay et al. (2016).

${ }^{25}$ We use plausexog programmed in Stata by Clarke et al. (2017), using the union of confidence interval approach for estimation of bounds.
} 
Table 4 IV-FE regression models of cognitive ability and total educational fees

\begin{tabular}{|c|c|c|c|c|}
\hline \multirow{2}{*}{$\begin{array}{l}\text { Dependent variable: } \\
\text { total educational } \\
\text { fees }\end{array}$} & \multicolumn{4}{|l|}{ IV-FE } \\
\hline & $\begin{array}{l}\text { Instruments: } \\
\text { rainfall at birth }\end{array}$ & $\begin{array}{l}\text { Instruments: } \\
\text { rainfall in } \\
\text { year } 1\end{array}$ & $\begin{array}{l}\text { Instruments: average } \\
\text { rainfall in the first } \\
\text { two years of life }\end{array}$ & $\begin{array}{l}\text { Instruments: } \\
\text { rainfall at birth and } \\
\text { rainfall in year } 1\end{array}$ \\
\hline \multirow{4}{*}{ Cognitive ability } & (1) & (2) & (3) & (4) \\
\hline & -0.034 & -0.045 & -0.038 & -0.039 \\
\hline & $(0.015)^{* *}$ & $(0.014)^{* * *}$ & $(0.013)^{* * *}$ & $(0.013)^{* * * *}$ \\
\hline & {$[0.017]^{* *}$} & {$[0.019]^{* *}$} & {$[0.017]^{* *}$} & {$[0.017]^{* *}$} \\
\hline $\begin{array}{l}\text { Anderson-Rubin } \\
\text { (AR) test }\end{array}$ & {$[-0.064,-0.011]$} & {$[-0.075,-0.025]$} & {$[-0.064,-0.019]$} & {$[-0.075,-0.019]$} \\
\hline$p$ value & 0.016 & 0.000 & 0.001 & 0.001 \\
\hline $\begin{array}{l}\text { Moreira CLR test } \\
p \text { value }\end{array}$ & - & - & - & $\begin{array}{l}{[-0.067,-0.023]} \\
0.000\end{array}$ \\
\hline $\begin{array}{l}\mathrm{K} \text { test } \\
p \text { value }\end{array}$ & - & - & - & $\begin{array}{l}{[-0.066,-0.023]} \\
0.000\end{array}$ \\
\hline $\begin{array}{l}\mathrm{J} \text { test } \\
p \text { value }\end{array}$ & - & - & - & $\begin{array}{l}\text { entire grid } \\
0.411\end{array}$ \\
\hline $\begin{array}{l}\mathrm{K}-\mathrm{J} \text { test } \\
p \text { value }\end{array}$ & - & - & - & $\begin{array}{l}{[-0.069,-0.022]} \\
0.000\end{array}$ \\
\hline Observations & 1402 & 1402 & 1402 & 1402 \\
\hline $\begin{array}{l}\text { Nr. excluded } \\
\text { instruments }\end{array}$ & 1 & 1 & 1 & 2 \\
\hline
\end{tabular}

Robust standard errors in parentheses; community clustered standard errors in brackets. *p<0.10, **p< $0.05, * * * p<0.01$. The dependent variable is standardised total educational fees. Child controls are age in months, square of age in months, cubic of age in months, maternal age at birth, birth order, height-forage $Z$-score in round 3, birthplace, birth quarter, birth year and the type of sibling. The AR test, CLR test, $\mathrm{K}$ test, $\mathrm{J}$ test and K-J test are all robust to heteroskedasticity. All the tests give confidence intervals at $90 \%$ confidence level. The AR test and K-J test are a joint test of the structural parameter $\beta$ and the exogeneity of the instruments, where K and CLR only test the former. The K-J test is more efficient than the AR test. $\mathrm{K}$ test and CLR test are more powerful than AR test. Unlike the K test, the K-J test and CLR test do not suffer from the problem of spurious power losses. The $\mathrm{J}$ test is like the Hansen $\mathrm{J}$ test of weak exogeneity, giving a confidence set where all values of $\beta$ that are consistent with the assumption of weak exogeneity of instrument variables

auto-correlated with contemporary parental responses-our outcome variable. We argue that if such auto-correlation exists, the direction will be positive, if parental investment strategy is consistent over time. In particular, we assume that parents would not switch from reinforcement in early life to compensation in later life. Therefore, if early compensation effort exists, the difference of parental investment would be negatively correlated with the difference of rainfall in early life. To generate a robust estimate under this prior (Conley et al. 2012), we allow departures from the assumption of strict exogeneity of rainfall so that rainfall could have a non-zero and 
direct impact on parental investment, whose size is in the interval of $[-\delta, \delta]{ }^{26}$ They relax this restriction so that $\gamma$ is not necessarily zero, but in the bounds of $[-\delta, \delta]$, allowing us to see whether this direct effect is large enough to render the IV estimate insignificant. As shown in Fig. 8, we identify the lower bound of the direct effect which would render the second-stage estimate of the interest parameter insignificant at a $10 \%$ confidence level. The results show that if the lower bound is greater than -0.003 , the second-stage estimate would be significant. As the overall reduced-form effect of rainfall on parental response is -0.0059 , we are confident that the lower bound of the model still is significant, given that the direct effect would have to be greater than $51 \%$ of the overall effect to render the IV point estimate insignificant. ${ }^{27}$

To further allay the concern of rainfall having a long-term effect on consumption, in the robustness check shown in row 11 of Table 6 , we also provide results on whether the idiosyncratic rainfall during the period when children are aged between 0 and 2 years old has a direct impact on consumption in the future at household level, and this is not significant.

Another related threat to the exclusion restriction would arise if rainfall in one sibling's infancy affects the other's ability (earlier or later than the critical periods in question). Therefore, we regress ability on rainfall exposure of both own and sibling rainfall shock in infancy, while replacing the household fixed effects by county fixed effects since estimating coefficients on own and sibling rainfall exposure would not be possible in a family fixed-effects model. Shown in Table 8, the estimates of rainfall during infancy of the sibling are insignificant and the magnitude is as small as a tenth of the one of our interest variable (in absolute value). The coefficient of a child's 'own' rainfall during the first 2 years of life remains significant and large in magnitude after including the sibling's rainfall.

Finally, we consider that parents' education decision may be influenced not only by cognitive development but also by the child's health. To address this concern, we add current health to the vector of controls. Removing HAZ does not change our results, as shown in row 10 of Table 6 . We also considered health as an alternative main variable of interest, given that early rainfall may also affect health, and nutrition can be proxied by height-for-age. We therefore reran our main model with HAZ in 2009 as the proxy for child 'ability'. Rainfall was a weak instrument for HAZ, and the second-stage results were insignificant. ${ }^{28}$ This echoes the health literature which shows that children may recover from early height deficits by mid-childhood, but cognitive ability in mid-childhood is still highly correlated with early nutrition (Casale and Desmond 2016).

We compare our results with others using the IV-FE approach to examine parental responses. We noted some limitations of Frijters et al. (2013) handedness instrument earlier. In addition, the traditional Cragg-Donald $F$ statistic of 12.32 under

\footnotetext{
${ }^{26}$ Following Conley et al. (2012)'s 'plausible exogeneity' test, we propose a model derived from (1), $\Delta I_{h}=\beta \Delta C A_{h}+\gamma \Delta R_{h}+\Delta X_{h} \Lambda+\Delta \epsilon_{h}$, where difference in rainfall has a non-zero impact on parental responses. In the conventional IV approach, $\gamma$ is set to be zero. Conley et al. (2012) note that in theory if we know $\gamma$ we could subtract it from both sides of the equation and continue with a consistent IV estimate.

${ }^{27}$ The overall reduced-form is estimated using the model $\Delta I_{h}=\gamma \Delta R_{h}+\Delta X_{h} \Lambda+\Delta \epsilon_{h}$.

${ }^{28}$ See Table 11 for full results.
} 
the assumption of an i.i.d. error only satisfies the 'rule of thumb' marginally, and arguably fails to provide strong evidence that handedness is a valid instrument to identify child's ability. On the contrary, Leight (2017)'s grain yield instrument is robust to the existence of weak instrument using the $p$ value from an AR test.

More generally, our finding of a strong negative relationship between cognitive ability and cognitive resources is consistent with a number of studies finding that parents prefer inequality aversion (Behrman 1988; Bharadwaj et al. 2018; Rosenzweig and Wolpin 1988; Del Bono et al. 2012; Frijters et al. 2009; Halla et al. 2014; Leight 2017; Yi et al. 2015).

\subsection{Heterogeneity of parental responses to children's early ability}

After studying the parental response at an aggregate level, we now explore heterogeneities in responses by stratifying the sample by maternal education, household size and wealth. Splitting the sample according to endogeneous characteristics is not an ideal solution; however, we follow the existing literature on this topic for more developed countries than Ethiopia (Cabrera-Hernandez 2016; Hsin 2012; Grätz and Torche 2016; Restrepo 2016), given that the heterogeneous characteristics we are interested in are fixed at the household level, so these cannot be interacted in the IV model; we interpret our results here with some caution.

Table 5 suggests that the association between early ability and later cognitive resources does vary by family socio-economic standing (models 2-7). Specifically, the point estimates show high-SES parents provide more cognitive stimulation to their low-ability child, whereas low-SES parents compensate less cognitive investment in ability between their children. This heterogeneous variation in parental responses across SES is consistent using three indicators of socio-economic standing (maternal education, household size and family wealth). We should emphasise that the Young Lives sample is already a 'pro-poor' sample from communities that are relatively poor, in a country that is poor by global standards (Outes-Leon and Sanchez 2008).

Table 5 shows that among better-off parents (educated mothers, small household or high family wealth), a one standard deviation increase in ability leads to 5.3 to $6.3 \%$ of a standard deviation decrease in total educational fees, while worse-off parents only compensate 2.1 to $2.7 \%$ of a standard deviation more educational investment to the low-ability child. Given the size of the standard errors, there is some overlap in the $95 \%$ confidence intervals for the point estimates, which means we cannot conclude definitively that they are significantly different, but given the fairly small sample sizes, we do consider the evidence as strongly suggestive. In comparison, using a sibling FE model, Hsin (2012) and Restrepo (2016) suggest a compensating effect among high-educated mothers by providing more time and more cognitive and emotional stimulations to the low-birth-weight children in the USA. The result is also consistent with Cabrera-Hernandez (2016) which uses a sibling FE model and finds out higher-educated mothers compensate expenditure in school for the low-birthweight outcome in Mexico. However, Grätz and Torche (2016) use a twin FE model and find that advantaged families provide more cognitive stimulation to higher-ability children, and lower-class parents do not respond to ability differences in the USA. 
Table 5 IV-FE model of the effects of cognitive ability on total educational fees: potential heterogeneity effect by SES

\begin{tabular}{|c|c|c|c|c|c|c|c|}
\hline & \multirow[b]{2}{*}{$\begin{array}{l}\text { All } \\
(1)\end{array}$} & \multicolumn{2}{|c|}{ Maternal education } & \multicolumn{2}{|c|}{ Household size } & \multicolumn{2}{|c|}{ Family wealth } \\
\hline & & $\begin{array}{l}\text { No } \\
\text { (2) }\end{array}$ & $\begin{array}{l}\text { Yes } \\
(3)\end{array}$ & $\begin{array}{l}\text { Large } \\
\text { (4) }\end{array}$ & $\begin{array}{l}\text { Small } \\
(5)\end{array}$ & $\begin{array}{l}\text { Low } \\
\text { (6) }\end{array}$ & $\begin{array}{l}\text { High } \\
\text { (7) }\end{array}$ \\
\hline Cognitive ability & $\begin{array}{l}-0.039 \\
(0.013)^{* * *} \\
{[0.017]^{* *}}\end{array}$ & $\begin{array}{l}-0.024 \\
(0.009)^{* * *} \\
{[0.013]^{*}}\end{array}$ & $\begin{array}{l}-0.053 \\
(0.025)^{* *} \\
{[0.028]^{*}}\end{array}$ & $\begin{array}{l}-0.027 \\
(0.012)^{* *} \\
{[0.013]^{* *}}\end{array}$ & $\begin{array}{l}-0.053 \\
(0.023)^{* *} \\
{[0.032]}\end{array}$ & $\begin{array}{l}-0.021 \\
(0.008)^{* * *} \\
{[0.012]^{*}}\end{array}$ & $\begin{array}{l}-0.063 \\
(0.028)^{* *} \\
{[0.033]^{*}}\end{array}$ \\
\hline \multicolumn{8}{|l|}{ Weak instrument test: } \\
\hline \multicolumn{8}{|l|}{ MP critical values: } \\
\hline $5 \%$ of worst case bias & 5.808 & 7.153 & 11.130 & 8.111 & 7.805 & 7.502 & 12.098 \\
\hline $10 \%$ of worst case bias & 4.550 & 5.333 & 7.678 & 5.892 & 5.721 & 5.542 & 8.247 \\
\hline $20 \%$ of worst case bias & 3.828 & 4.276 & 5.668 & 4.601 & 4.505 & 4.400 & 6.010 \\
\hline \multicolumn{8}{|l|}{ Wald test of estimates: } \\
\hline $\begin{array}{l}\chi(1)^{2} \\
\text { Prob }>\chi^{2}\end{array}$ & & $\begin{array}{l}1.18 \\
0.272\end{array}$ & & $\begin{array}{l}0.98 \\
0.321\end{array}$ & & $\begin{array}{l}2.01 \\
0.157\end{array}$ & \\
\hline Observations & 1402 & 758 & 644 & 664 & 738 & 792 & 610 \\
\hline
\end{tabular}

Robust standard errors in parentheses. Clustered standard errors by community in brackets. $* p<0.10$, $* * p<0.05, * * * p<0.01$. Same model is used as the main model. The IVs used are rainfall at birth and rainfall in year 1

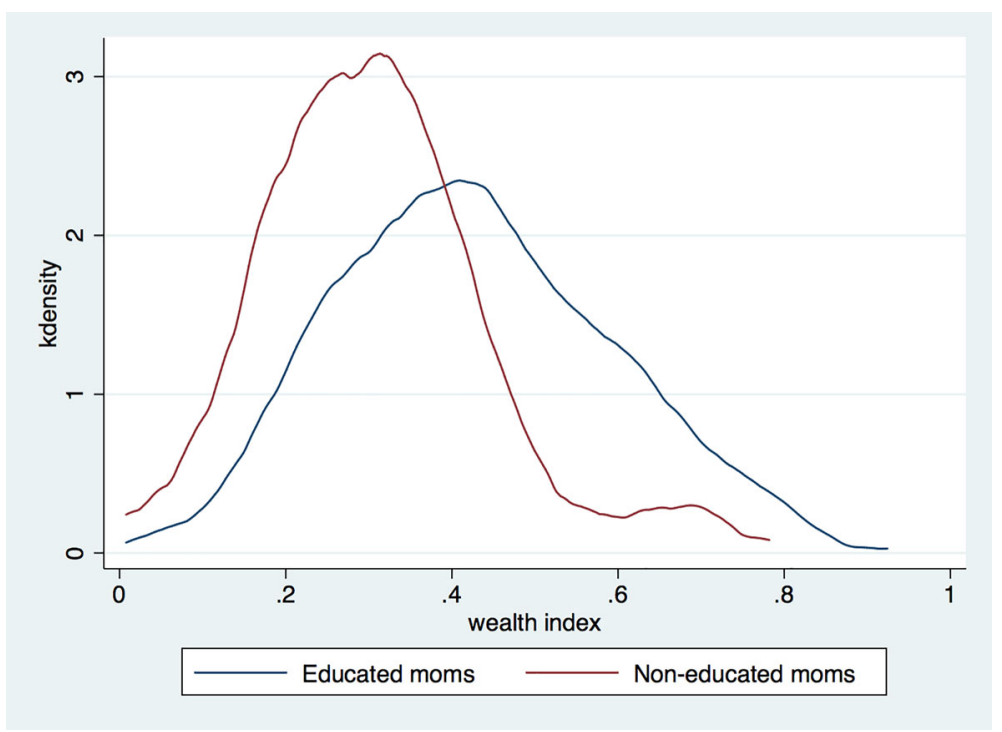

Fig. 7 Kernel density plot of household wealth index by maternal education, 2013 
An unanswered question based on the existing findings is that whether the heterogeneous result by maternal education is caused by the difference in wealth, in differential preferences for compensation or ability to observe a difference in the cognitive outcomes of the siblings. Figure 7 shows that on average, mothers with education are generally better off in terms of wealth, implying that educated mothers might have a higher capacity to compensate disadvantaged children, simply because they have sufficient financial resources.

\subsection{Robustness checks}

We now present some additional robustness tests. First, we restrict the sibling pairs to have an age gap larger than 2 years, i.e. the older sibling should be born at least 3 years earlier than the younger one, in order to avoid a direct relationship between the rainfall shock experienced by one and outcome of the other. For example, one could argue that if one child is born 1 year after the older sibling, the rainfall experienced by the older one in the second year of life would be the rainfall the next child experiences in the first year of life; also, when the newborn child is exposed to an adverse shock at birth, the parent might reallocate the resources immediately among the children, which would directly influence the nutritional input of the older child in the second year of life. The restricted sample has 844 observations. In row 1 of Table 6 , the first-stage coefficient of rainfall in the first 2 years of life equals $0.187(t=5.67)$, which is only slightly larger than the one of full sample presented in Table 3. The full diagnostics of the first stage using restricted sample are shown in Table 10, which are consistent with the results of the full sample. The secondstage estimate equals $-0.036(z=-2.57)$, very close to the one in full sample which equals -0.038 . To conclude, it is consistent with the previous result that parents compensate disadvantaged children by offering higher educational resources to them. This can also serve as a suggestive evidence that there is not much difference in the compensation effect when siblings are further separated in age.

In row 2, we re-estimate our model without the covariates (i.e. maternal age, birth order, birth year, birth quarter, HAZ, birthplace and the type of sibling), only controlling for age. The IV-FE estimate equals $-0.045(z=-2.81)$. This result provides extra support for our assumption that rainfall is exogenously determined because it shows that our estimate is not conditional on the set of control variable included in the model.

In row 3, we show results using only the private tuition fees as the dependent variable and find consistent results, which are higher in magnitude. When parents observe an increase of one standard deviation in ability, they reduce private tuition fees by $9.9 \%$ of a standard deviation. Next, we investigate whether the likelihood to take private tuition is contingent upon cognitive ability, using a dummy variable of taking private tuition as the dependent variable. Shown in row 4, the result suggests a compensating behaviour of parents: the probability of offering private tuition to a child will increase by $30.8 \%$ if the child is underdeveloped by one standard deviation in cognitive ability.

We also exploit child time use as a potential measure for educational investment. Firstly, we study parental responses using study hours. Row 5 shows that the 
Table 6 Robustness regression models

\begin{tabular}{|c|c|c|c|}
\hline Model variations & $\begin{array}{l}\text { Obs rainfall from } \\
0-24 \text { months on ability }\end{array}$ & First stage: average & $\begin{array}{l}\text { Second stage: ability on } \\
\text { parental responses }\end{array}$ \\
\hline $\begin{array}{l}\text { (1) Siblings born at least } \\
3 \text { years apart }\end{array}$ & 844 & $\begin{array}{l}0.187 * * * \\
(0.033)\end{array}$ & $\begin{array}{l}-0.036^{* * *} \\
(0.014) \\
{[-0.062,-0.014]}\end{array}$ \\
\hline (2) Only control for age & 1402 & $\begin{array}{l}0.143 * * * \\
(0.027)\end{array}$ & $\begin{array}{l}-0.045^{* * *} \\
(0.016) \\
{[-0.078,-0.022]}\end{array}$ \\
\hline $\begin{array}{l}\text { (3) Private tuition } \\
\text { fees as outcome }\end{array}$ & 1402 & $\begin{array}{l}0.156^{* * *} \\
(0.027)\end{array}$ & $\begin{array}{l}-0.099 * * * \\
(0.036) \\
{[-0.167,-0.045]}\end{array}$ \\
\hline $\begin{array}{l}\text { (4) Having private tuition } \\
\text { (dv) as outcome }\end{array}$ & 1402 & $\begin{array}{l}0.156^{* * *} \\
(0.027)\end{array}$ & $\begin{array}{l}-0.308 * * * \\
(0.085) \\
{[-0.480,-0.187]}\end{array}$ \\
\hline $\begin{array}{l}\text { (5) Study hours at } \\
\text { home as outcome }\end{array}$ & 1402 & $\begin{array}{l}0.156^{* * *} \\
(0.027)\end{array}$ & $\begin{array}{l}-0.542 * * \\
(0.251) \\
{[-1.000,-0.150]}\end{array}$ \\
\hline $\begin{array}{l}\text { (6) Care, chore, task, work } \\
\text { hours as outcome }\end{array}$ & 1402 & $\begin{array}{l}0.156^{* * *} \\
(0.027)\end{array}$ & $\begin{array}{l}0.425 * \\
(0.254) \\
{[0.029,0.888]}\end{array}$ \\
\hline $\begin{array}{l}\text { (7) Siblings born at } \\
\text { the same place }\end{array}$ & 1392 & $\begin{array}{l}0.156^{* * * *} \\
(0.027)\end{array}$ & $\begin{array}{l}-0.038 * * * \\
(0.013) \\
{[-0.064,-0.019]}\end{array}$ \\
\hline $\begin{array}{l}\text { (8) Siblings both younger } \\
\text { than } 8 \text { in R3 }\end{array}$ & 1220 & $\begin{array}{l}0.164 * * * \\
(0.029)\end{array}$ & $\begin{array}{l}-0.040^{* * *} \\
(0.013) \\
{[-0.065,-0.021]}\end{array}$ \\
\hline (9) Siblings both enrolled & 1170 & $\begin{array}{l}0.155^{* * *} \\
(0.027)\end{array}$ & $\begin{array}{l}-0.038 * * * \\
(0.013) \\
{[-0.064,-0.019]}\end{array}$ \\
\hline (10) Not control for HAZ & 1402 & $\begin{array}{l}0.165^{* * *} \\
(0.029)\end{array}$ & $\begin{array}{l}-0.039 * * * \\
(0.013) \\
{[-0.065,-0.019]}\end{array}$ \\
\hline (11) Rainfall on consumer index & 1402 & $\begin{array}{l}-0.005 \\
(0.009)\end{array}$ & \\
\hline
\end{tabular}

$* p<0.10, * * p<0.05, * * * p<0.01$. Models 1 to 10 use the same IV-FE model as the one for the main result in Table 4, instrumenting the ability using average rainfall during the first 2 years of life, whilst Model 11 uses cross-section OLS estimation. Robust standard errors in parentheses. The weak IV robust AR confidence intervals are in the brackets in column 3. Row 1 uses a sub-sample which contains the sibling pairs which have an age gap of at least 3 years. Row 2 removes all the covariates displayed in Table 4 apart from age of child. Row 3 uses private tuition fees as dependent variable. Row 4 uses whether the child receives private tuition as the outcome variable. Row 5 exploits child study hours at home as outcome variable. Row 6 uses summary of hours spent by child in care, chore, task and work as outcome variable. Row 7 restricts the sample to siblings born at the same place. Row 8 restricts the sample to siblings both younger than 8 in round 3. Row 9 restricts the sample to siblings both enrolled. Row 10 removes height-for-age $Z$-score as control in the model. Row 11 is the OLS estimation regressing consumer durable index on the average rainfall from 0 to 24 months 
coefficient is negative and significant, with the estimate equal to $-0.542(z=$ -2.16), suggesting a child's study hours will increase by $54.2 \%$ of a standard deviation if the child's ability is one standard deviation lower. In row 6, we examine parental responses in respect to child hours spent in caring, doing chores and tasks and working, and find the coefficient being a positive and significant, with the estimate equals $0.425(z=1.68)$, suggesting a child might spend more time in care, chores, tasks and work by $42.5 \%$ of standard deviation when the child's ability is higher by one standard deviation. This implies consistent compensating parental responses in terms of child time use.

We restrict the sample to siblings born in the same place and find no change in the coefficient, with the estimate equals to $-0.038(z=-2.92)$, as shown in row 7 . In row 8 , when the sample is restricted to children younger than 8 (i.e. the index child is paired with a young sibling), the coefficient does not change much, with the estimate equal to $-0.040(z=-3.08)$. In row 9 , the compensating effect is consistent using a sub-sample of siblings both enrolled in school, as the estimate equals to $-0.038(z$ $=-2.92$ ). In row 10, we drop the control of HAZ in the specification, and it does not change the result; the estimate is $-0.039(z=-3.00)$.

In row 11, we regress the household consumer durables index in round 4 on rainfall in early life and find no significant effect $(t=0.56)$, implying that rainfall shocks in early life do not have a persistent impact on consumption patterns of the household in the later life of children. This supports our assumption that rainfall in early life does not affect parental investment in later life through a direct mechanism.

Finally, we checked the difference in increment of outcomes of the two siblings between round 5 (2016) and round 4 (2013), to examine whether the investment differential did close the gap in ability. In a difference-in-difference specification, we found the coefficient on investment was negative and statistically insignificant, with a $p$ value of 0.24 . So, at least in the 3 -year period, attempts to compensate were largely unsuccessful which may be (i) due to the relatively small magnitude of the difference in investments (3.9\% of a standard deviation at the mean), or (ii) because the low level of early ability constrains the return to later investment, consistent with Heckman's (2007) hypothesis of dynamic complementarities in the human capital production function.

\section{Conclusion}

We find that for a sample of poor Ethiopian households, on average, parental investment compensates weakly for a low-ability outcome. We use an instrumental variable approach combined with panel data and a sibling fixed-effects model to provide robust evidence. This is of policy relevance since the results suggest that the detrimental effects of early life shocks might be mediated or muted by parental responses and hence the biological effects of early nutritional shocks might be larger than policymakers observe. In addition, it complements the literature on reduced-form estimates of the total effect of an early life shock or adverse event on final adult health in Ethiopia (e.g. Dercon and Porter (2014)). 
This finding is in line with results from some previous studies reporting compensating parental behaviour (Behrman 1988; Bharadwaj et al. 2018; Rosenzweig and Wolpin 1988; Del Bono et al. 2012; Frijters et al. 2009; Halla et al. 2014; Leight 2017; Yi et al. 2015). It is also consistent with the intrafamily resource allocation model introduced by Behrman et al. (1982), suggesting parents favour equity over efficiency.

However, we have indicative evidence that this effect varies across family SES. Relatively advantaged parents provide more cognitive investment to lower-ability children, and lower-class families exhibit only small and modest compensatory behaviours. The finding is consistent across all measures of parental socio-economic advantage (maternal education, household wealth and household size), though the 95\% confidence intervals for the estimates overlap. Consistent with prior findings, mothers with higher education compensate for lower-endowed children (CabreraHernandez 2016; Hsin 2012; Restrepo 2016).

Our results therefore complement the literature which studies whether the effect of shocks to early ability can be eliminated or mitigated through investments, which themselves depend on family socio-economic status. Most studies have found that compared with the low-ability children born in higher-class families, the low-ability child born in lower-class families have worse outcomes in adulthood. One hypothesis in the literature is that parental involvement plays a role in reinforcing the poor ability outcome. Specifically, higher-class parents compensate for the differences in ability, or at least are not reinforcing the differences. Our results support the hypothesis that parental investment varies by family SES, even in a context of low-income by international standards. What is difficult, given the high correlation between SES as measured by wealth and by parental education, is to differentiate whether high-SES parents are more able to observe the difference in ability or more able to compensate for the difference, or both of these. More work on this issue is needed where suitable data can be collected.

Acknowledgement The authors would like to thank the anonymous referees for helpful comments and suggestions. Their views are not necessarily those of Young Lives, the University of Oxford, DFID or other funders. Thanks to Liang Bai, Amalavoyal Chari, Marta Favara, Kalle Hirvonen, Pascal Jaupart, Tatiana Kornienko, Jessica Leight, Patricia Espinoza Revollo, and Mark Schaffer for helpful suggestions, and to seminar and conference participants in Young Lives, Jun 2017; SGPE conference, Jan 2018; CSAE conference, Mar 2018; University of Sussex, Mar 2018; UNICEF Ethiopia, Apr 2018; SEHO conference, May 2018; SMYE, May 2018 and ESPE, June 2018.

\section{Compliance with Ethical Standards}

Conflict of interest The authors declare that they have no conflict of interest.

Disclaimer The views expressed here are those of the author(s). All errors and omissions are our own.

Open Access This article is distributed under the terms of the Creative Commons Attribution 4.0 International License (http://creativecommons.org/licenses/by/4.0/), which permits unrestricted use, distribution, and reproduction in any medium, provided you give appropriate credit to the original author(s) and the source, provide a link to the Creative Commons license, and indicate if changes were made. 


\section{Appendix A: Tables}

Table 7 Full list of coefficients from Table 4

Dependent variable: total educational fees

IV-FE result

Cognitive ability

$-0.038^{* *}$

(0.017)

First born

$-0.484 * * *$

(0.107)

Second born

$-0.441 * * *$

(0.096)

Third born

$-0.395^{* * *}$

(0.083)

Forth born

$-0.343 * * *$

(0.071)

Fifth born

$-0.281 * * *$

(0.058)

Sixth born

$-0.232 * * *$

(0.046)

Seventh born

$-0.162 * * *$

(0.032)

Eighth born

$-0.115^{* * *}$

(0.021)

Ninth born

$-0.054 * * *$

(0.012)

Old sister with young brother

$0.060 * * *$

(0.015)

Old brother with young sister

$0.054 * * *$

(0.015)

Old brother with young brother

$0.069 * * *$

(0.017)

Old sister with young sister

$0.066^{* * * *}$

(0.016)

HAZ in round 3

0.003

(0.002)

Born in first quarter

$-0.005$

(0.017)

Born in second quarter

$-0.005$

(0.013)

0.001

(0.008)

0.012

(0.017) 
Table 7 (continued)

Dependent variable: total educational fees

IV-FE result

Square of age in months

$-0.000$

Cubic of age in months

Cubic of age in months

Maternal age at birth

Maternal age at birth

Constant

$* p<0.10, * * p<0.05, * * * p<0.01$. Full list of main results in column 3 of Table 4, instrumenting the ability using average rainfall during the first 2 years of life. Community clustered standard errors in parentheses. Birth order's reference group is tenth born. Birth quarter's reference group is born in fourth quarter. Birth year and birthplace are not shown in this table, but controlled in the regressions

Table 8 Robustness check: first-stage results adding sibling rainfall in infancy using community fixedeffects model

Cognitive ability

Child average rainfall in the first two years of life

Sibling average rainfall in the first 2 years of life

$$
\begin{aligned}
& 0.124 \\
& (0.032)^{* * *}
\end{aligned}
$$

Child-level controls

Household-level controls

Mother-level controls

Community fixed effects

Observations

$R^{2}$

$$
\begin{aligned}
& \text { Yes } \\
& \text { Yes } \\
& \text { Yes } \\
& \text { Yes } \\
& 1402 \\
& 0.674
\end{aligned}
$$$$
\text { Yes }
$$$$
\text { Yes }
$$$$
\text { Yes }
$$

Yes
Yes
Yes
Yes
1402
0.674

$* p<0.10, * * p<0.05, * * * p<0.01$. Robust standard errors are in parentheses. This table reports analogous regression as the one in the first-stage regression. The dependent variable is cognitive ability. Children controls are age in months, square of age in months, cubic of age in months, maternal age at birth, birth order, birthplace, birth quarter, birth year, language and the type of sibling (such as born as an older sister and paired with a younger brother). Household-level controls are household size, wealth index and gender of household head. Mother-level controls are a series of levels of maternal education 
Table 9 Redundancy tests: cognitive ability and cognitive resources

\begin{tabular}{lll}
\hline Dependent variable: & IV-FE & \\
\cline { 2 - 3 } total educational fees & $\begin{array}{l}\text { Instruments: rainfall } \\
\text { from in utero to year } 2\end{array}$ & $\begin{array}{l}\text { Instruments: rainfall } \\
\text { at birth and in year } 1\end{array}$ \\
\hline Cognitive ability & $-0.033^{* * * *}$ & $-0.039^{* * *}$ \\
& $(0.011)$ & $(0.013)$ \\
Weak identification test: & & \\
Moutiel-Pflueger effective $F$ stat & 11.025 & 17.169 \\
Moutiel-Pflueger critical values: & & 5.808 \\
5\% of worst case bias & 21.195 & 4.550 \\
10\% of worst case bias & 12.773 & 3.828 \\
20\% of worst case bias & 8.182 & \\
IV redundancy test: & & - \\
Redundancy of rainfall in utero, $p$ value & 0.270 & 0.003 \\
Redundancy of rainfall at birth, $p$ value & 0.000 & 0.005 \\
Redundancy of rainfall in year $1, p$ value & 0.006 & - \\
Redundancy of rainfall in year $2, p$ value & 0.007 & 1402 \\
Observations & 4 & 2 \\
Nr. Excluded Instruments & & \\
\hline
\end{tabular}

$* p<0.10, * * p<0.05, * * * p<0.01$. Robust standard errors in parentheses. Children controls are age, maternal age at birth, height-for-age $Z$-score, birthplace, birth quarter, birth order, birth year and the type of sibling. IV redundancy test is a LM test of a specified instrument, asking whether this instrument provides useful information to identify the equation. The null hypothesis is the instrument does not contribute to the asymptotic efficiency of the equation. Rejecting the null suggests that the specified instrument does capture information of the endogenous variable 
Table 10 Robustness check: first-stage results using restricted sample

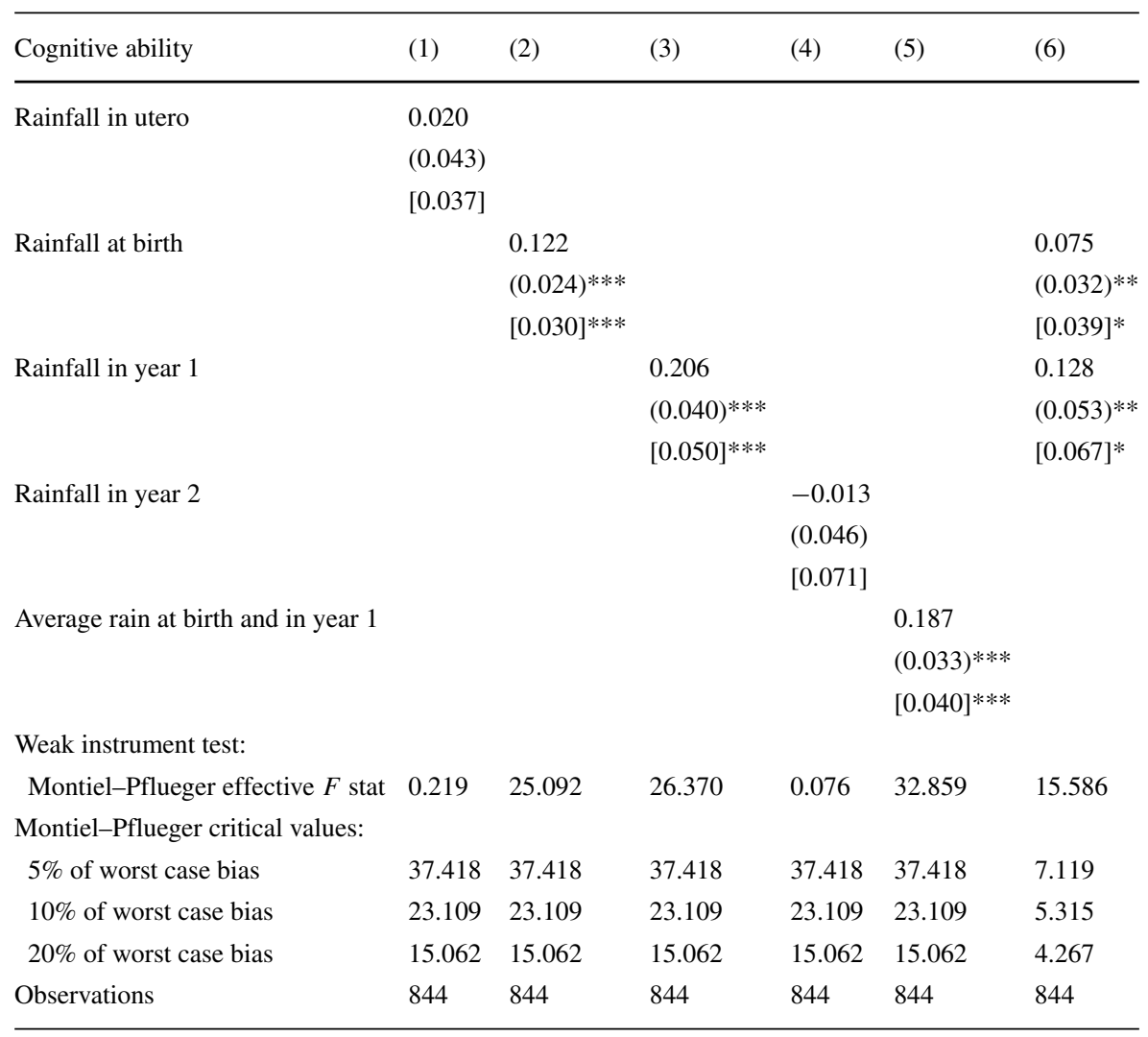

$* p<0.10, * * p<0.05, * * * p<0.01$. Robust standard errors in parentheses. Clustered standard errors by community are in brackets. These are within-household fixed effects estimates from the first stage of the IV-FE model, same as the one in Table 3. This sub-sample contains the sibling-pairs which have an age gap of at least 3 years. Controls are age, maternal age at birth, birth order, birthplace, birth quarter, birth year, height-for-age in round 3 and the type of sibling (such as born as an older sister and paired with a younger brother) 


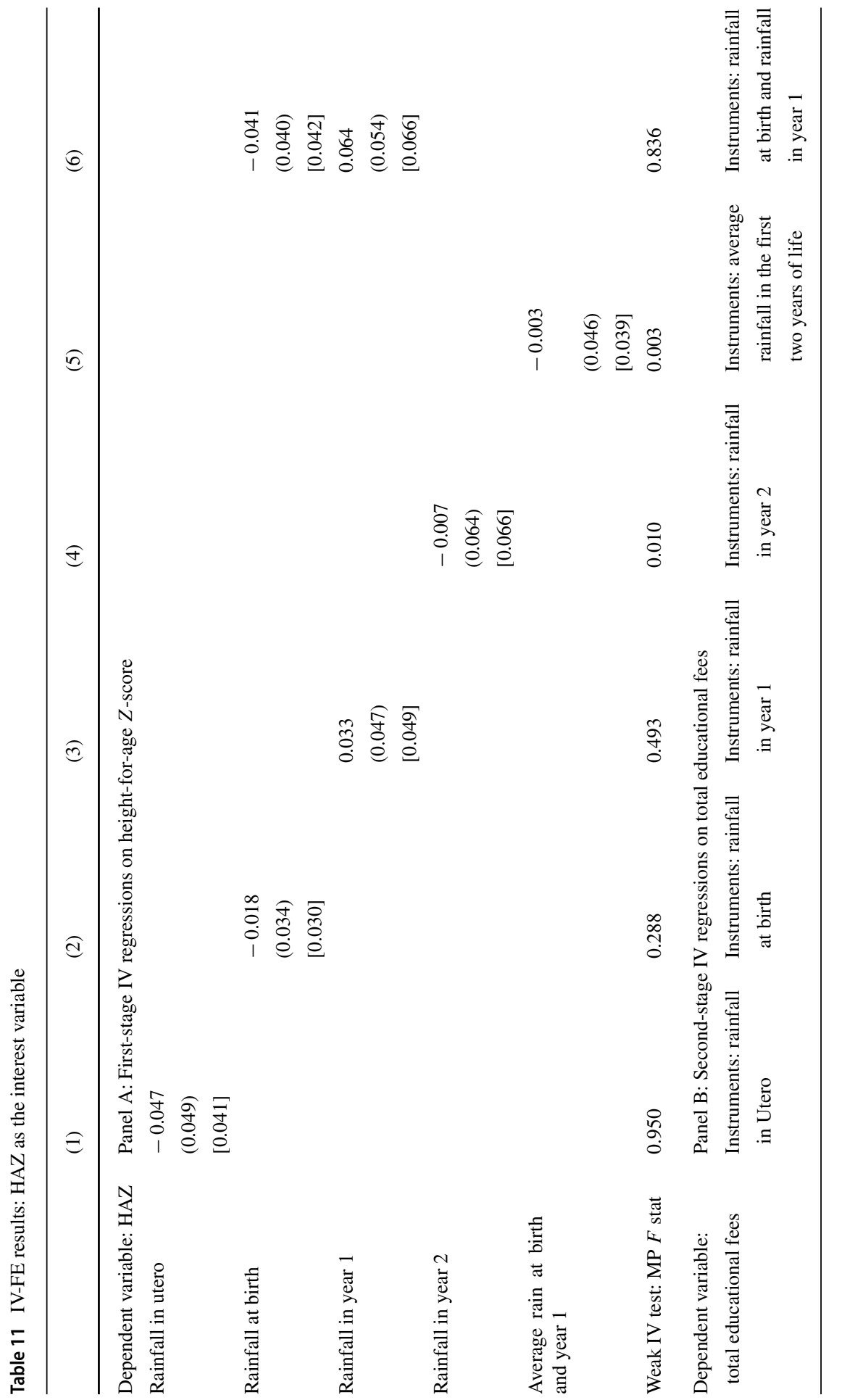




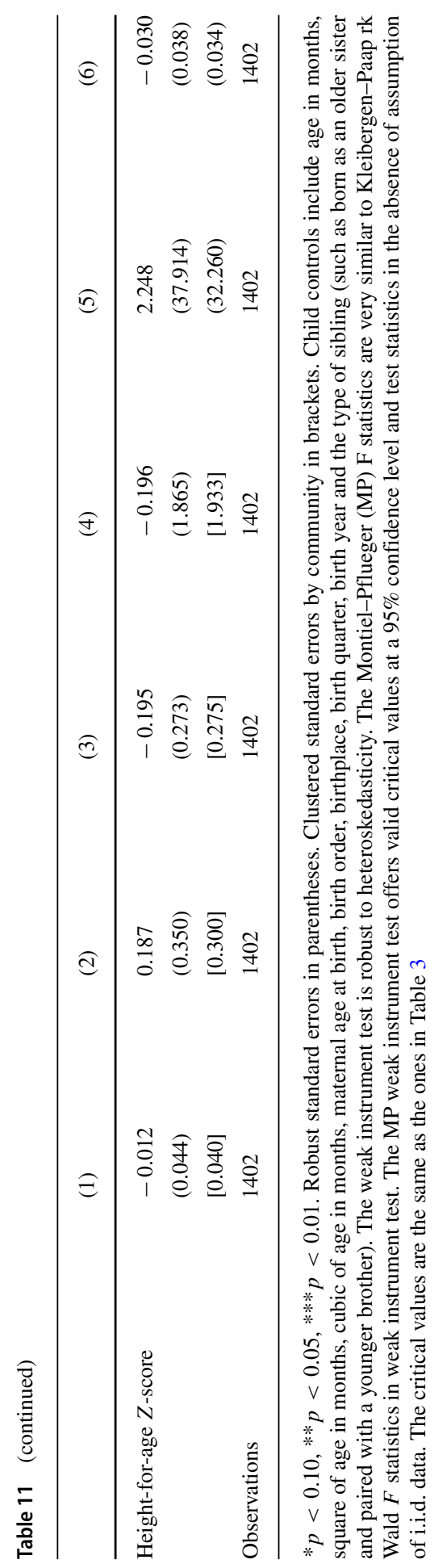




\section{Appendix B: Graphs}

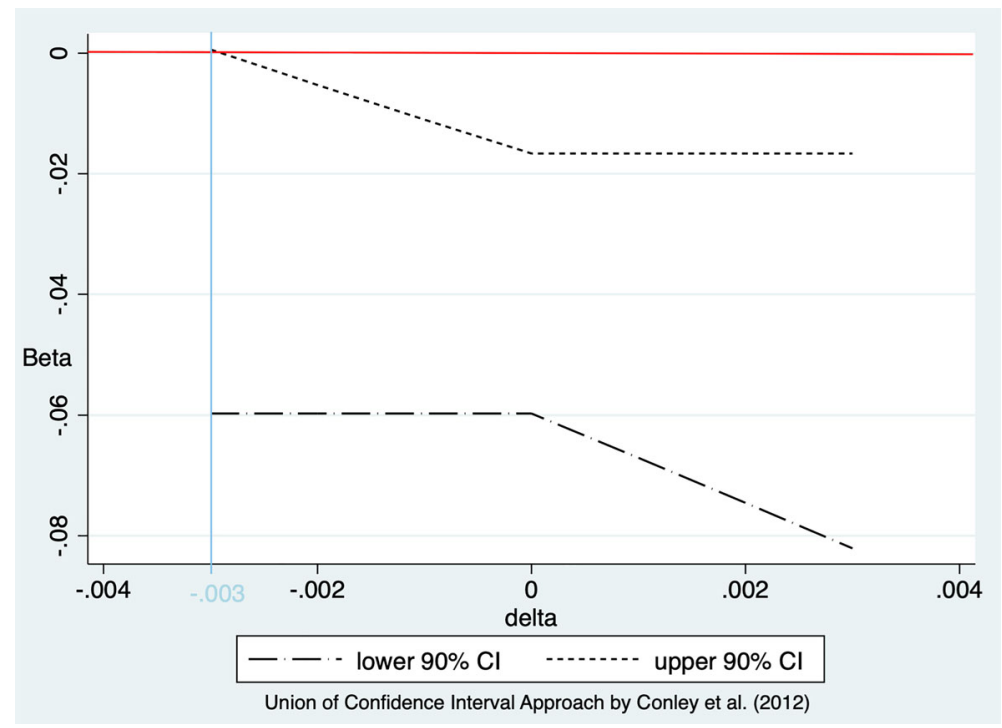

Fig. 8 Estimated $\beta$ by direct effect of instrument

\section{References}

Abufhele A, Behrman J, Bravo D (2017) Parental preferences and allocations of investments in children's learning and health within families. Soc Sci Med 194:76-86

Adhvaryu A, Nyshadham A (2016) Endowments at birth and parents' investments in children. Econ J 126(593):781-820

Aizer A, Cunha F (2012) The production of human capital: endowments, investments and fertility. Technical report, National Bureau of Economic Research

Almond D, Currie J (2011) Killing me softly: the fetal origins hypothesis. J Econ Perspect 25(3):153-172

Almond D, Currie J, Duque V (2018) Childhood circumstances and adult outcomes: act II. J Econ Lit 56(4):1360-1446

Almond D, Mazumder B (2013) Fetal origins and parental responses. Annual Review of Economics 5(1):37-56

Angrist JD, Pischke J-S (2008) Mostly harmless econometrics: an empiricist's companion. Princeton University Press, Princeton

Ayalew T (2005) Parental preference, heterogeneity, and human capital inequality. Econ Dev Cult Chang 53(2):381-407

Barnett I, Ariana P, Petrou S, Penny ME, Duc LT, Galab S, Woldehanna T, Escobal JA, Plugge E, Boyden J (2012) Cohort profile: the Young Lives study. Int J Epidemiol 42(3):701-708

Becker GS (1991) A treatise on the family. Harvard University Press, Cambridge

Becker GS, Tomes N (1976) Child endowments and the quantity and quality of children. J Polit Econ 84(4, Part 2):S143-S162

Behrman J (1988) Nutrition, health, birth order and seasonality: intrahousehold allocation among children in rural India. J Dev Econ 28(1):43-62

Behrman J, Pollak RA, Taubman P (1982) Parental preferences and provision for progeny. J Polit Econ 90(1):52-73 
Behrman J, Rosenzweig MR, Taubman P (1994) Endowments and the allocation of schooling in the family and in the marriage market: the twins experiment. J Polit Econ 102(6):1131-1174

Bhalotra SR, Clarke D (2018) The twin instrument: fertility and human capital investment. The twin instrument: fertility and human capital investment. IZA Institute of Labor Economics Discussion Paper 11878

Bharadwaj P, Eberhard J, Neilson C (2018) Health at birth, parental investments, and academic outcomes. J Labour Econ 36(2)

Bound J, Solon G (1999) Double trouble: on the value of twins-based estimation of the return to schooling. Econ Educ Rev 18(2):169-182

Buckles K, Kolka S (2014) Prenatal investments, breastfeeding, and birth order. Soc Sci Med 118:66-70

Cabrera-Hernandez F (2016) The accident of birth: effects of birthweight on educational attainment and parents' compensations among siblings. Center for Economic Research and Teaching (CIDE)

Campbell J (1998) Book review: Peabody picture vocabulary test. J Psychoeduc Assess 16(4):334-338

Casale D, Desmond C (2016) Recovery from stunting and cognitive outcomes in young children: evidence from the South African birth to twenty cohort study. J Dev Orig Health Dis 7(2):163-171

Clarke D et al (2017) Plausexog: Stata Module to implement Conley et al's plausibly exogenous bounds. Statistical Software Components

Conley D (2008) Bringing sibling differences in: Enlarging our understanding of the transmission of advantage in families. Social class: how does it work? pp 179-200

Conley TG, Hansen CB, Rossi PE (2012) Plausibly exogenous. Rev Econ Stat 94(1):260-272

Crookston BT, Schott W, Cueto S, Dearden KA, Engle P, Georgiadis A, Lundeen EA, Penny ME, Stein AD, Behrman J (2013) Postinfancy growth, schooling, and cognitive achievement: Young Lives. Am J Clin Nutr 98(6): 1555-1563

Cueto S, Leon J (2012) Psychometric characteristics of cognitive development and achievement instruments in round 3 of Young Lives, Technical Report 15, Young Lives

Currie J, Almond D (2011) Human capital development before age five. In: Handbook of labor economics, vol 4. Elsevier, pp 1315-1486

Datar A, Kilburn MR, Loughran DS (2010) Health endowments and parental investments in infancy and early childhood. Demography 47(6):145-162

Del Bono E, Ermisch J, Francesconi M (2012) Intrafamily resource allocations: a dynamic structural model of birth weight. J Labor Econ 30(3):657-706

Dendir S (2014) Children's cognitive ability, schooling and work: evidence from Ethiopia. Int J Educ Dev 38:22-36

Dercon S, Porter C (2014) Live aid revisited: long-term impacts of the 1984 Ethiopian famine on children. J Eur Econ Assoc 12(4):927-948

Doyle O, Harmon CP, Heckman JJ, Tremblay RE (2009) Investing in early human development: timing and economic efficiency. Econ Hum Biol 7(1):1-6

Dunn LM, Dunn LM (1997) PPVT-III: Peabody picture vocabulary test. American Guidance Service

Finlay K, Magnusson L, Schaffer ME et al (2016) Weakiv: Stata module to perform weak-instrumentrobust tests and confidence intervals for instrumental-variable (IV) estimation of linear, probit and tobit models. Statistical software components

Frijters P, Johnston DW, Shah M, Shields MA (2009) To work or not to work? Child development and maternal labor supply. Am Econ J Appl Econ 1(3):97-110

Frijters P, Johnston DW, Shah M, Shields MA (2013) Intrahousehold resource allocation: do parents reduce or reinforce child ability gaps? Demography 50(6):2187-2208

Glewwe P, Jacoby HG, King EM (2001) Early childhood nutrition and academic achievement: a longitudinal analysis. J Public Econ 81(3):345-368

Grätz M, Torche F (2016) Compensation or reinforcement? The stratification of parental responses to children's early ability. Demography 53(6):1883-1904

Griliches Z (1979) Sibling models and data in economics: beginnings of a survey. J Polit Econ 87(5, Part 2): S37-S64

Halla M, Zweimüller M et al (2014) Parental response to early human capital shocks: evidence from the Chernobyl Accident, Technical report, The Austrian Center for Labor Economics and the Analysis of the Welfare State. Johannes Kepler University Linz, Austria

Heckman JJ (2007) The economics, technology, and neuroscience of human capability formation. Proc Natl Acad Sci USA, 13250-13255 
Hill RV, Porter C (2017) Vulnerability to drought and food price shocks: evidence from Ethiopia. World Dev 96:65-77

Hsin A (2012) Is biology destiny? Birth weight and differential parental treatment. Demography 49(4):1385-1405

Kleibergen F, Paap R (2006) Generalized reduced rank tests using the singular value decomposition. J Econ 133(1):97-126

Lareau A (2011) Unequal childhoods: class, race, and family life, University of California Press, Berkeley

Leight J (2017) Sibling rivalry: endowment and intrahousehold allocation in Gansu Province, China. Econ Dev Cult Chang 456-493

Leon J, Singh A (2017) Equating test scores for receptive vocabulary across rounds and cohorts in Ethiopia, India and Vietnam, Technical report, Young Lives

Lynch JL, Brooks R (2013) Low birth weight and parental investment: do parents favor the fittest child? J Marriage Fam 75(3):533-543

Maccini S, Yang D (2009) Under the weather: health, schooling, and economic consequences of early-life rainfall. Am Econ Rev 99(3):1006-1026

Nicoletti C, Salvanese K, Tominey E (2018) Response of parental investments to child's health endowment at birth. Health Economics (Contributions to Economic Analysis, Vol. 294), Emerald Publishing Limited, pp. 175-199. https://doi.org/10.1108/S0573-855520180000294009

Olea JLM, Pflueger C (2013) A robust test for weak instruments'. J Bus Econ Stat 31(3):358-369

Oumer J (2009) The challenges of free primary education in Ethiopia, UNESCO. International Institute for Educational Planning

Outes-Leon I, Sanchez A (2008) An assessment of the Young Lives sampling approach in Ethiopia, Technical Report 1, Young Lives

Paxson C, Schady N (2007) Cognitive development among young children in Ecuador the roles of wealth, health, and parenting. J Hum Resour 42(1):49-84

Pflueger C, Wang S (2015) A robust test for weak instruments in Stata. Stata J 15(1):216-225

Price J (2008) Parent-child quality time: does birth order matter? J Hum Resour 43(1):240-265

Restrepo BJ (2016) Parental investment responses to a low birth weight outcome: who compensates and who reinforces? J Popul Econ 29(4):969-989

Rosales-Rueda MF (2014) Family investment responses to childhood health conditions: intrafamily allocation of resources. J Health Econ 37:41-57

Rosenzweig MR, Wolpin KI (1988) Heterogeneity, intrafamily distribution, and child health. J Hum Resour, 437-461

Schaffer ME et al (2015) Xtivreg2: Stata Module to perform extended IV/2SLS, GMM and AC/HAC, LIML and k-class regression for panel data models. Statistical Software Components

Staiger D, Stock JH et al (1997) Instrumental variables regression with weak instruments. Econometrica 65(3):557-586

UNICEF (2009) Abolishing school fees in Africa lessons from Ethiopia, Ghana, Kenya, Malawi, and Mozambique

Victora CG, de Onis M, Hallal PC, Blössner M, Shrimpton R (2010) Worldwide timing of growth faltering: revisiting implications for interventions. Pediatrics pp peds-2009

Yi J, Heckman JJ, Zhang J, Conti G (2015) Early health shocks, intra-household resource allocation and child outcomes. Econ J 125(588):F347-F371

Publisher's note Springer Nature remains neutral with regard to jurisdictional claims in published maps and institutional affiliations. 